\title{
Razões de isótopos estáveis em um testemunho de firn do manto de gelo da Antártica Oriental
}

\author{
Flavia A. TAVARES ${ }^{1,2}$, Jefferson C. SIMÕES ${ }^{1,2,3}$, Ronaldo T. BERNARDO², \\ Nicoli P. GERHARD ${ }^{1,2}$, Gino CASASSA ${ }^{4}$ \& Luciano MARQUETTO ${ }^{1,2}$

\begin{abstract}
1 Programa de Pós-graduação em Geociências, Universidade Federal do Rio Grande do Sul. Av. Bento Gonçalves, 9.500, CEP 91.540-000, Porto Alegre, RS Brasil. (flaviaalvestavares@hotmail.com) Av. Bento Gonçalves, 9.500, CEP 91.540-000, Porto Alegre, RS, Brasil (ronaldo.bernardo@ufrgs.br, nicoligerhard@gmail.com, luciano.marquetto@gmail.com)
\end{abstract} \\ ${ }^{2}$ Centro Climático e Polar, Instituto de Geociências, Universidade Federal do Rio Grande do Sul. \\ ${ }^{3}$ Climate Change Institute, University of Maine. Orono, ME 04469-5790, EUA. (jefferson.simoes@ufrgs.br) \\ 4 Universidad de Magallanes. Av. Pdte. Manuel Bulnes 01855, Punta Arenas, Chile (gino.casassa@gmail.com)
}

\begin{abstract}
Resumo. O testemunho de firn IC-02 (88 $01^{\prime} 21,3^{\prime \prime} \mathrm{S}$ e $\left.82^{\circ} 04^{\prime} 21,7^{\prime \prime} \mathrm{W}\right)$, atingindo $41,82 \mathrm{~m}$ de profundidade, foi coletado no manto de gelo da Antártica Oriental, durante uma travessia científica chileno-brasileira no verão austral de 2004/2005. Este estudo visou à determinação da variabilidade sazonal das razões isotópicas de oxigênio e hidrogênio $\left(\delta^{18} \mathrm{O}\right.$ e $\left.\delta \mathrm{D}\right)$ e da taxa anual de acumulação de neve. 0 testemunho foi subamostrado em um sistema de fusão contínua e o conteúdo isotópico determinado por espectrometria a laser de cavidade ressonante do tipo ring-down (WS-CRDS, sistema Picarro). A série de $\delta^{18} \mathrm{O}$ varia entre $-50,77 \%$ e $-41,40 \%$ (média $-46,39 \pm 1,37 \%$ ), enquanto o $\delta D$ varia entre $-408,18 \%$ e $-323,85 \%$ (média $-367,43 \pm$ $12,51 \%$ ). 0 excesso de deutério (d) tem média de 4,36 $\pm 2,66 \%$. O testemunho representa $85 \pm$ 3 anos de acumulação de neve, ou seja, uma taxa média de $152 \pm 64 \mathrm{~mm}$ ano-1 em equivalente d'água. A partir da década de 1990 ocorreu a diminuição da média anual de $\delta \mathrm{D}$ concomitante com o aumento da taxa de acumulação de neve (17\% entre 1974 e 2003). 0 aumento desta acumulação poderia estar associado à maior mobilização de neve à deriva (drift snow) até o sítio de deposição, associada à maior advecção de massas de ar oceânicas vindas dos mares antárticos (Amundsen, Bellingshausen, Weddell e Lazarev). Tal interpretação é apoiada pelo aumento da velocidade dos ventos zonais, conforme observado nos campos de anomalias de altura geopotencial, vento zonal e temperatura em $500 \mathrm{mb}$ da reanálise NCEP/NCAR.
\end{abstract}

Palavras-chave. Antártica, testemunho de firn, isótopos estáveis.

Abstract. Stable isotope ratios in a fiRn CORE from the EAST ANTARCTIC ICE SheEt.

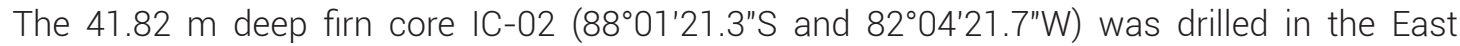
Antarctic ice sheet during a Chilean-Brazilian scientific traverse in the Austral summer of $2004 / 2005$. This study aimed to determine the stable water isotopes $\left(\delta^{18} \mathrm{O}\right.$ e $\left.\delta \mathrm{D}\right)$ and the snow annual accumulation annual rate. The core was subsampled in a continuous fusion system and the isotopic content determined by a ring-down resonant cavity laser spectrometry (WS-CRDS, Picarro system). The $\delta^{18} \mathrm{O}$ series ranges from $-50.77 \%$ to $-41.40 \%$ (mean $-46.39 \pm 1.37 \%$ ), while the $\delta \mathrm{D}$ ranges from $-408.18 \%$ to $-323.85 \%$ (mean $-367.43 \pm 12.51 \%$ ). The excess of deuterium (d) has an average of $4.36 \pm 2.66 \%$. The core represents $85 \pm 3$ years of snow accumulation, that is, an average rate of $152 \pm 64 \mathrm{~mm}$ year-1 in water equivalent. From the 1990s onwards, there was a decrease in the mean annual $\delta \mathrm{D}$ concomitant with an increase in the snow accumulation rate (17\% from 1974 to 2003). The increase in this accumulation could be associated with a greater mobilization of drift snow to the deposition site, associated with a greater advection of oceanic air masses coming from the Antarctic seas (Amundsen, Bellingshausen, Weddell and Lazarev). Such interpretation is supported by the increase in the zonal winds velocity, as observed in anomalies fields of geopotential height, zonal wind and temperature at $500 \mathrm{mb}$ in the NCEP / NCAR reanalysis.

Keywords. Antarctica, firn core, stable isotopes. 


\section{Introdução}

O continente Antártico tem papel essencial na circulação atmosférica e oceânica (Simões et al., 2011) e guarda a maior quantidade de água doce congelada do mundo. No atual momento de mudanças ambientais intensificadas pela ação humana (Jouzel \& Masson-Delmotte, 2010), entender a variabilidade climática antártica dos últimos 200 anos favorece a compreensão das mudanças ocorridas em outras latitudes, além de possibilitar a elaboração de cenários para as próximas décadas.

O estudo de testemunhos de gelo (ou de neve ou firn) tornou-se importante nas últimas décadas, pois o gelo da Antártica e da Groenlândia provê indiretamente (by proxy) o melhor arquivo natural das variações na composição química da atmosfera por serem locais onde toda a precipitação é preservada, além de possuírem os mais profundos pacotes de neve e gelo (espessura média de 2.020 m; Simões et al., 2011). O limite entre a neve e o firn (estágio intermediário entre a neve e o gelo) não é bem definido, geralmente identificado por características tais como cristais soldados uns aos outros, mas onde ainda persiste a conexão dos espaços intergranulares (ou seja, ainda é permeável). O limite firn-gelo, por sua vez, é marcado pelo fechamento da conexão entres os poros e ocorre quando a densidade atinge $0,83 \mathrm{~g} \mathrm{~cm}^{-3}$ (Simões, 2004). A neve que forma as geleiras e mantos de gelo é constituída por cristais de gelo, por impurezas líquidas e sólidas, e por gases retidos em bolhas intergranulares. Ao perfurar verticalmente uma massa de gelo, é possível determinar as propriedades físicas e o conteúdo químico do gelo amostrado em função da profundidade e, portanto, do tempo. O conteúdo químico do gelo é registrado de três maneiras diferentes: na composição isotópica de moléculas de água, nas concentrações de impurezas presentes na neve e no gelo e no conteúdo de bolhas de ar isoladas no gelo (Wolff, 2012).

Dentre as técnicas mais consagradas do estudo de testemunhos de gelo, está a determinação da variabilidade do conteúdo de isótopos estáveis que formam a neve e o gelo glacial. A neve $\left(\mathrm{H}_{2} \mathrm{O}\right)$ é formada por átomos de hidrogênio e oxigênio, mas na natureza vários isótopos estáveis desses dois elementos existem concomitantemente: o hidrogênio possui dois isótopos estáveis ( ${ }^{1} \mathrm{H} \mathrm{e}{ }^{2} \mathrm{H}, \mathrm{O}$ deutério). Já O oxigênio ocorre na forma de três isótopos $\left({ }^{16} \mathrm{O}\right.$, ${ }^{17} \mathrm{O}$ e $\left.{ }^{18} \mathrm{O}\right)$. A tabela 1 apresenta as proporções relativas da ocorrência desses isótopos estáveis na natureza.

Isótopos estáveis da água em testemunho de gelo na Antártica são a chave para expandir o que se tem documentado sobre mudanças do clima no espaço e tempo nas regiões polares. A interpretação isotópica serve para inferir temperaturas passadas (Lorius et al., 1969) e auxilia na compreensão do ciclo da água no passado recente e durante as variações glaciaisinterglaciais (Jouzel et al., 1997, 2007).

Tabela 1. Abundância dos isótopos estáveis de hidrogênio e oxigênio na natureza (modificado de Faure \& Mensing, 2005).

Table 1. Hydrogen and oxygen stable isotopes abundance in nature (modified from Faure \& Mensing, 2005).

\begin{tabular}{cc}
\hline Isótopo & Abundância (\%) \\
\hline & Hidrogênio \\
${ }_{1}^{1} \mathrm{H}$ & 99,985 \\
${ }_{1}^{2} \mathrm{H}$ & 0,015 \\
& Oxigênio \\
${ }_{8}^{16} \mathrm{O}$ & 99,762 \\
${ }_{8}^{17} \mathrm{O}$ & 0,038 \\
${ }_{8}^{18} \mathrm{O}$ & 0,200 \\
\hline
\end{tabular}

A distribuição espacial dos isótopos estáveis é influenciada por diferentes fatores, tais como: a sazonalidade da precipitação, o local fonte da evaporação, o transporte do vapor d'água e os processos pós-deposicionais. Isso torna complexa a reconstrução de mudanças climáticas no passado por meio de registros isotópicos em testemunhos de gelo. A evaporação que acontece no oceano é o primeiro estágio da precipitação que chega à Antártica, e marca o início do fracionamento no vapor d'água acima do local fonte. A precipitação vai, gradualmente, sofrer o processo de condensação durante o seu transporte sobre a Antártica dentro de certas 
condições de temperatura, pressão e umidade, concomitante ao fracionamento dos isótopos estáveis. A observação simultânea das razões de isótopos estáveis no vapor atmosférico acima da interface superfície-atmosfera, próximo ao solo, e na superfície de neve são importantes para entender o papel de processos pós-deposicionais no fracionamento (Hou et al., 2012).

o registro das razões isotópicas em um testemunho de gelo pode ser afetado por efeitos sistêmicos causados por processos pós-deposicionais da neve. O principal deles é a ablação, que inclui derretimento, evaporação, desprendimento, erosão eólica e avalanchas, que causam perda de massa seja na forma de neve, gelo ou água (Simões, 2004), acentuado em locais com complexa topografia local. A sublimação do gelo, ou seja, mudança de estado físico do gelo de sólido direto para vapor, também é fator importante em áreas de clima seco (Ekaykin et al., 2002; Frezzotti et al., 2004, 2007; Neumann \& Waddington, 2004).

A composição isotópica da neve antártica pode refletir o local de origem da massa de ar e a condição de evaporação associada, mudanças na relação entre condensação e temperatura na superfície ou mudanças na intermitência da precipitação. Embora a interpretação do sinal isotópico da neve superficial tenha sido ponderada pela precipitação, estudos mais recentes evidenciam trocas isotópicas entre a superfície de neve antártica e a atmosfera, associadas às condições de metamorfismo da neve que ocorre em escala diurna e subanual (Casado et al., 2016; Touzeau et al., 2016; Goursaud et al., 2018).

Na Antártica, a taxa anual de precipitação de neve pode variar entre $15 \mathrm{~mm}$ equivalente d'água (note que a precipitação e acumulação de neve são apresentadas em equivalente d'água, ou seja, a coluna de precipitação de neve em um certo período de tempo multiplicada por sua densidade. Isso é necessário devido a variabilidade da densidade do pacote de neve) no alto platô da Antártica Oriental, a mais de $2.000 \mathrm{~mm}$ na costa ocidental da Península Antártica. As camadas depositadas em forma de neve sofrem metamorfismo para o gelo (passando pelo estado intermediário chamado firn) devido à pressão das camadas sobrepostas e recristalização. Assim, o manto de gelo antártico consiste em uma sequência de camadas horizontais de gelo depositadas anualmente que ficam mais finas com profundidade tanto pela pressão exercida pelas camadas sobrepostas como pela deformação visco-plástica do gelo (Cuffey \& Paterson, 2010), podendo atingir quase $5 \mathrm{~km}$ de espessura e conter sequências que cobrem centenas de milhares de anos (até o momento o testemunho de gelo mais antigo já recuperado tem 800.000 anos; Jouzel et al., 2007).

Devido à carência de dados glacioquímicos detalhados, em escala anual das últimas décadas, de determinados sítios da Antártica, este artigo procurou investigar a variabilidade isotópica de um testemunho de firn e gelo raso obtido no platô da Antártica Oriental no verão austral de 2004/2005 para especificamente: (1) determinar a variabilidade sazonal e anual das razões de isótopos de oxigênio e hidrogênio; (2) interpretar essas variações em termos de variações climáticas ao longo do tempo no sítio de coleta; (3) comparar os resultados com medidas similares em outras partes do continente, determinando variações espaciais (geográficas).

\section{2 Área, materiais e métodos}

\section{1 Localização da área de amostragem}

0 testemunho de firn/gelo IC-02, $88^{\circ} 01^{\prime} 21,3^{\prime \prime} \mathrm{S}$ e $82^{\circ} 04^{\prime} 21,7^{\prime \prime} \mathrm{W}$, possui $42,92 \mathrm{~m}$, foi recuperado a uma altitude de $2.621 \mathrm{~m}$ no platô do manto de gelo da Antártica Oriental, a 220 km do Polo Sul geográfico. A temperatura média anual na superfície deste sítio é de $-45,0 \pm 0,5^{\circ} \mathrm{C}$, determinada por sonda com resistência de prata para medir a temperatura da neve entre 10 e $12 \mathrm{~m}$ de profundidade. Este é o método tradicionalmente usado em Glaciologia, pois a essa profundidade as variações sazonais de temperatura já estão atenuadas (Cuffey \& Patterson, 2010). Esse testemunho foi obtido durante a travessia chileno-brasileira do programa ITASE (International Trans-Antarctic Scientific Expedition) na viagem de retorno que partiu do Polo Sul geográfico, ao longo de 1.150 km, em direção à estação chilena Tenente 
Parodi $\left(80^{\circ} 18,2^{\prime} \mathrm{S}, 81^{\circ} 23,3^{\prime} \mathrm{W}, 790 \mathrm{~m}\right)$ nos montes Patriot no verão austral de 2004/2005. Durante a travessia, outros cinco testemunhos de gelo foram obtidos (Fig. 1) os quais foram analisados por Bayer da Silva (2011), Hammes (2011), Marques (2012), Schwanck (2012), Marquetto (2013), Lindau (2014), Marques et al. (2014), Schwanck et al. (2014), Marquetto et al. (2015) e Lindau et al. (2016).

O local de perfuração (Fig. 2) foi escolhido principalmente devido a duas características: (1) é distante de áreas fontes de material crustal (as montanhas mais próximas estão a mais de 250 km de distância), reduzindo a contribuição antártica para a química local; (2) a região de amostragem está na zona de neve seca, onde o derretimento da neve precipitada é baixo ou não existente, o que possibilita a preservação da coluna de neve de forma contínua (Hammes, 2011). A espessura de gelo estimado para o sítio do IC-02 é de $2.200 \mathrm{~m}$, de acordo com Fretwell et al. (2013).

\subsection{Trabalhos de campo}

A perfuradora utilizada na obtenção do testemunho IC-02 foi do tipo FELICS (Fast Electromechanical Lightweight Ice Coring System), desenvolvida pela companhia suíça FS Inventor AG desde 1998. O equipamento é composto por três partes principais: a broca, o guincho e a fonte de alimentação, que possuem um peso líquido de $228 \mathrm{~kg}$ (Ginot et al., 2002). Todas as partes em contato com o gelo são feitas de alumínio anodizado, aço inoxidável, polietileno e polioximetileno (Delrin ${ }^{\circledR}$ DUPONT).

O testemunho IC-02 foi obtido por duas perfurações, separados em $0,5 \mathrm{~m}$ de distância em superfície, sendo que na primeira foi amostrada a neve/firn entre 0 e 20,29 m de profundidade, e na segunda entre 20,29 e 41,82 m. Foram obtidas 44 seções com $8,25 \mathrm{~cm}$ de diâmetro e aproximadamente $1 \mathrm{~m}$ de comprimento. Imediatamente após a coleta foi realizada a pesagem, com auxílio de uma balança eletrônica, modelo Bioprecisa BS3000A, com precisão de $0,1 \mathrm{~g}$, para determinar a densidade volumétrica de cada amostra e a variabilidade dessa com a profundidade. As seções foram ensacadas em tubo plástico de polietileno, colocadas em caixas de isopor para transporte aéreo da Antártica para Punta Arenas (Chile) e desta para o Climate Change Institute (CCI) na Universidade do Maine (EUA), mantidas sempre em estado sólido para posterior subamostragem.

\subsection{Métodos}

\subsubsection{Descontaminação e derretimento do testemunho}

O derretimento do testemunho e preparação das amostras foram feitos numa sala fria $\left(-20^{\circ} \mathrm{C}\right)$ limpa (classe 100) no CCI. A camada exterior de gelo do testemunho, com cerca de 2 a 4 mm, foi removida com uma faca de cerâmica para evitar a contaminação (Tao et al., 2001). O topo e a base de gelo do testemunho também foram removidos por conter riscos de terem tido contato com a perfuradora. 0 processo de derretimento de gelo foi feito num sistema de fusão de testemunho de gelo contínuo de alta resolução, desenvolvido por pesquisadores do $\mathrm{CCl}$ com base no modelo proposto de Röthlisberger et al. (2000). De acordo com Osterberg et al. (2006), esse sistema de derretimento permite a coleta de amostras para três tipos de análises, no caso sendo elas: cromatografia iônica líquida (IC), espectrometria de massa de plasma induzido (ICP-SFMS - Inductively Coupled Plasma Sector Field Mass Spectrometry) para concentração de elementos-traço e espectrometria a laser de cavidade ressonante do tipo ring-down (WS-CRDS - Wavelength-Scanned Cavity Ring Down Spectroscopy, sistema Picarro ${ }^{\odot}$ ) para determinação das razões de isótopos estáveis. Logo após a subamostragem, os frascos de coleta de água para análises isotópicas foram congelados e mantidos no estado sólido até a véspera da medição.

\subsubsection{Determinação das razões isotópicas}

No total, 1755 amostras do testemunho IC-02 tiveram as duas razões isotópicas, $\delta \mathrm{D}$ e $\delta^{18} \mathrm{O}$, determinadas pelo sistema WS-CRDS PICARRO L2130i com precisão de 0,9\% e 0,4\%, respectivamente, no Laboratório de 


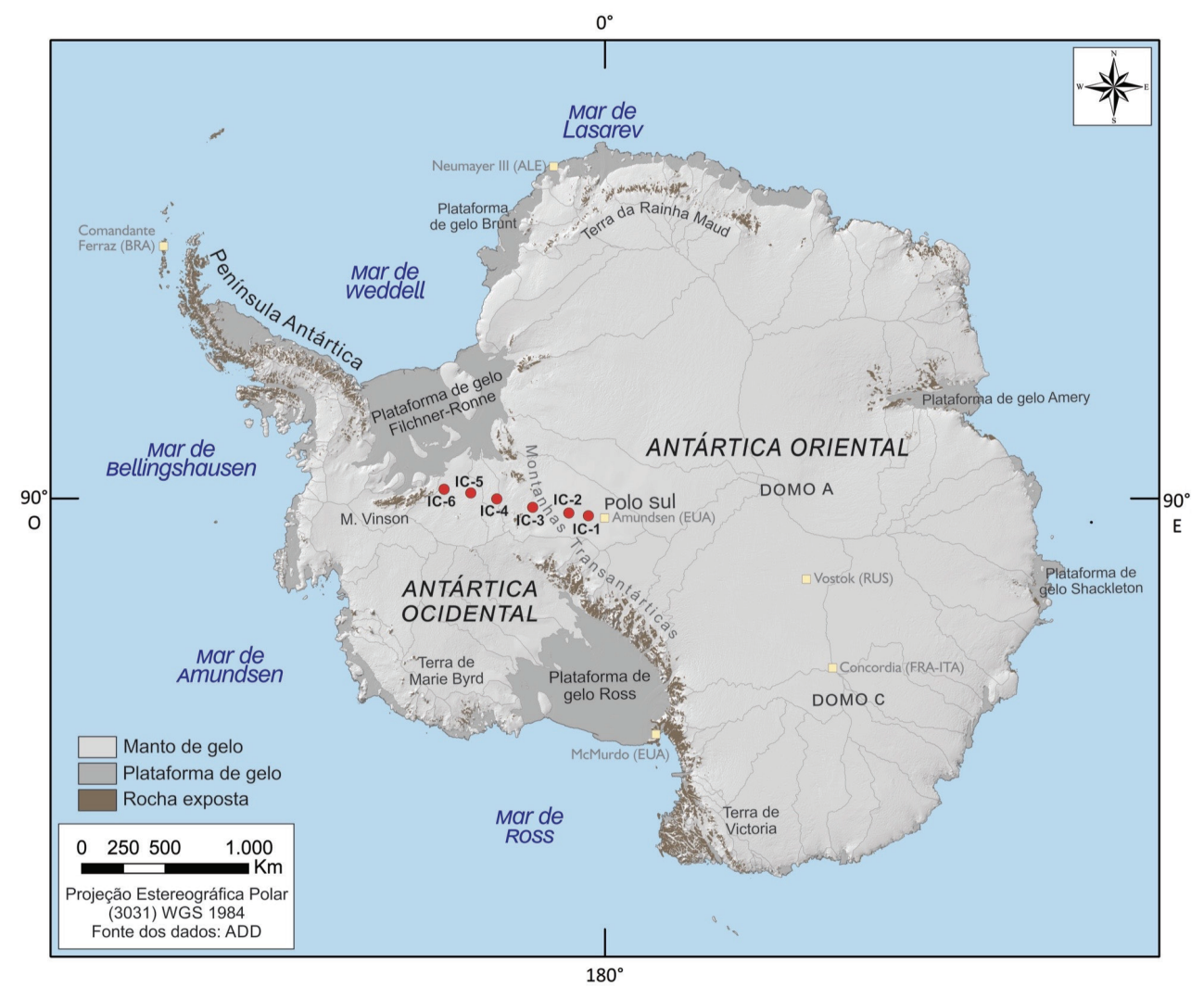

Figura 1. Mapa de localização dos seis testemunhos de neve e firn obtidos durante a travessia chileno-brasileira no verão austral de 2004/2005 (IC-1 a IC-6). Linhas cinzas fracas marcam os divisores de bacias de drenagem do manto de gelo antártico.

Figure 1. Location map of the six snow and firn cores obtained during the Chilean-Brazilian traverse in the 2004/2005 austral summer (IC-1 to IC-6). The weak gray lines mark the drainage basin dividers of the Antarctic ice sheet.

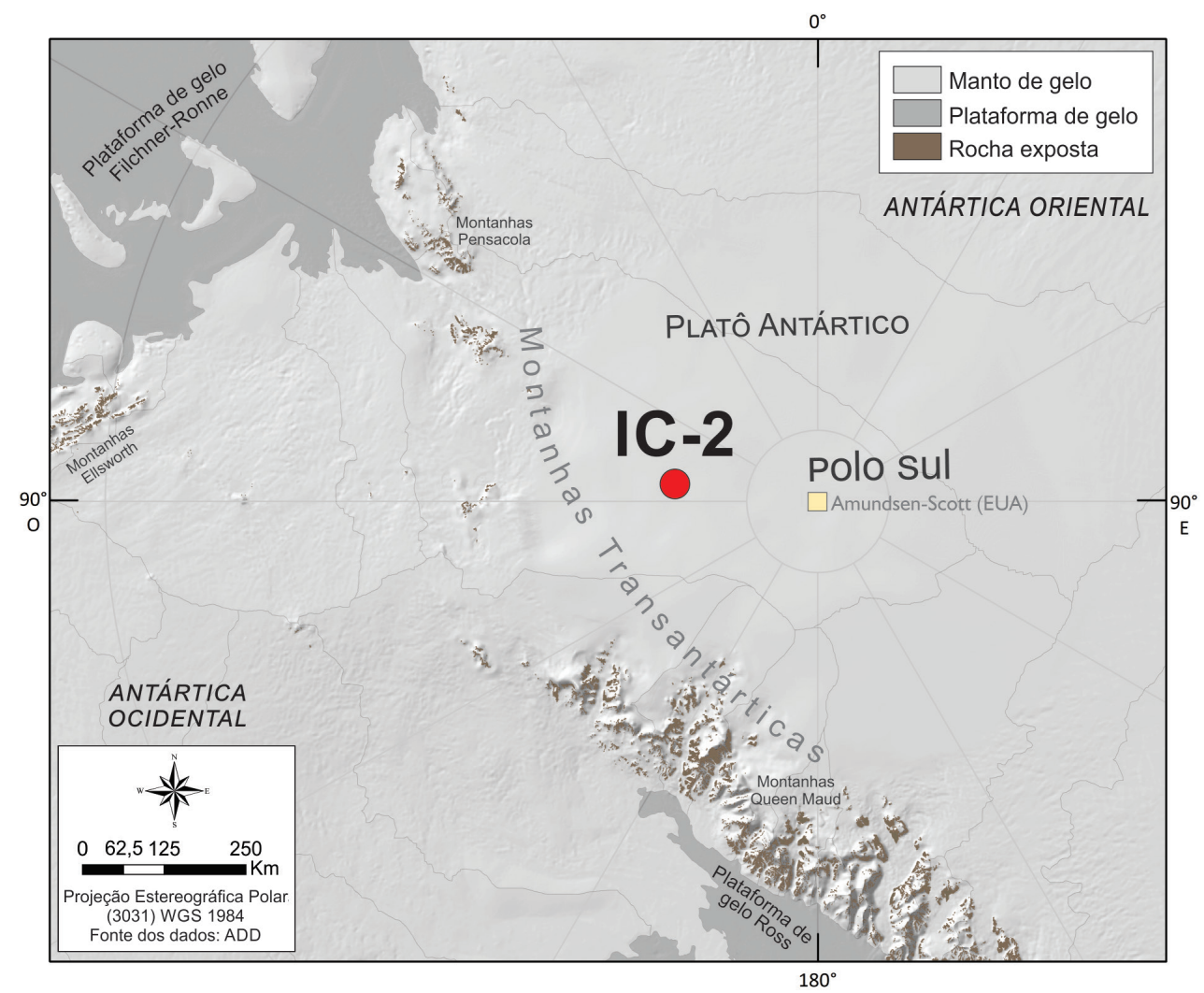

Figura 2. Mapa de localização do testemunho de neve/firn IC-02 no platô do manto de gelo da Antártica Oriental. Figure 2. Location map of IC-02 snow/firn core in the plateau of East Antarctic ice sheet. 
Glacioquímica do Centro Polar e Climático (CPC) da Universidade Federal do Rio Grande do Sul (Brasil). A principal vantagem dessa técnica é a habilidade de injetar diretamente a amostra em forma de vapor d'água na cavidade óptica do espectrômetro onde as razões isotópicas ${ }^{18} \mathrm{O} /{ }^{16} \mathrm{O}$ e ${ }^{2} \mathrm{H} /{ }^{1} \mathrm{H}$ são medidas simultaneamente. As técnicas de análise normalmente utilizadas em espectrômetro de massa das razões isotópicas (IRMS - Isotope Ratio Mass Spectrometry) não consideram a medida da água como tal, e acabam por convertê-la em um diferente gás antes de realizar a medição (Gehre et al., 1996; Huber \& Leuenberger, 2003).

A quantidade de isótopos estáveis de uma dada amostra de água é definida como a razão isotópica entre $\mathrm{O}^{18} \mathrm{O}$ e ${ }^{16} \mathrm{O}$, ou entre $\mathrm{O}^{1} \mathrm{H}$ e ${ }^{2} \mathrm{H}$, expressa em relação a um padrão de referência internacional (VSMOW - Vienna Standard Mean Ocean Water), em partes por mil (\%), segundo a expressão:

$\delta^{18} \mathrm{O}=\frac{\left({ }^{18} \mathrm{O} /{ }^{16} \mathrm{O}\right) \text { amostra }-\left({ }^{18} \mathrm{O} /{ }^{16} \mathrm{O}\right) \text { VSMOW }}{\left({ }^{18} \mathrm{O} /{ }^{16} \mathrm{O}\right) \text { VSMOW }} \times 10^{3} \%$

As amostras deste estudo foram normalizadas em relação à escala VSMOV e calibradas com os padrões SLAP (Standard Light Antarctic Precipitation) e GISP (Greenland Ice Sheet Precipitation) seguindo as recomendações da International Atomic Energy Agency (IAEA).

As razões isotópicas de oxigênio e hidrogênio eram inicialmente expressas com base na amostra padrão SMOW (Standard Mean Ocean Water), considerada como ponto zero da escala $\delta$ um corpo d'água hipotético, formada de amostras de água coletadas entre 500 e 2000 m de profundidade em áreas de oceano aberto no Atlântico, Pacífico e Índico (Craig, 1961). Mas como havia muitas amostras padrões e sem controle, o SMOW foi descontinuado e um novo padrão, o VSMOW, fabricado em laboratório e distribuído internacionalmente (Coplen, 1994; Hornberger, 1995). Devido à exaustão das amostras do padrão VSMOW, em 2006 a International Atomic Energy Agency (IAEA) lançou o padrão VSMOW2, idêntico ao primeiro. Os resultados de $\delta^{18} \mathrm{O}$ para amostras de água continuam sendo apresentados relativamente ao padrão VSMOW (IAEA, 2009).

\subsubsection{Determinação da temperatura atmosférica superficial}

A temperatura atmosférica superficial média anual na região do Polo Sul geográfico foi obtida pela média dos dados de superfície da estação Amundsen-Scott ( $90^{\circ} \mathrm{S} ; 2.835 \mathrm{~m}$ de altitude), desde o ano de 1957. Todos eles são disponibilizados no site do Scientific Committee on Antarctic Research (SCAR).

\subsubsection{Dados de reanálise}

Os dados de reanálise utilizados neste trabalho são produzidos em conjunto pelo National Centers for Environmental Prediction (NCEP) e National Center for Atmospheric Research (NCAR) e foram obtidos no site da NOAA ESRL Physical Sciences Division (PSD). As informações sobre a temperatura atmosférica media $\left({ }^{\circ} \mathrm{C}\right)$, zona de ventos $\left(\mathrm{m} \mathrm{s}^{-1}\right)$ e altura geopotencial da atmosfera $(\mathrm{m})$ do continente antártico compreendem o período de janeiro de 1957 a dezembro de 2018. Os modelos gerados apresentam a composição média e a anomalia dessa variação.

\section{Resultados}

\subsection{Estratigrafia do testemunho IC-02}

A determinação do perfil de densidade do testemunho IC-02 e o exame visual das seções do testemunho permitiu a construção do perfil estratigráfico (Fig. 3), que apesar de ser formado por um mesmo material (água no estado sólido), apresenta diferentes denominações conforme suas características físicas. Além disso, a estratigrafia visual auxilia na datação do testemunho, pois as camadas visíveis da neve apresentam deposições resultantes das condições meteorológicas no momento de precipitação na superfície (Langway, 1970).

A densidade do IC-02 no seu fundo atinge $0,66 \mathrm{~g} \mathrm{~cm}^{-3}$, ou seja, não chega o limite da transição de firn para gelo (densidade de $0,83 \mathrm{~g} \mathrm{~cm}^{-3}$ em que se adquire "zero permeabilidade"; Langway et al., 1993). Considerando a baixa temperatura do sítio 
de perfuração do IC-2, raras foram as lentes milimétricas de gelo formadas, que ocorrem quando um filme da superfície é derretido pela radiação solar direta. Este fenômeno ocorre até $-20^{\circ} \mathrm{C}$.

Nesse testemunho foram frequentemente observadas camadas com cristais de neve facetados em forma de prismas ou pirâmides, com granulometria mais grossa (2 a $5 \mathrm{~mm}$ ) intercalados com camadas de neve mais fina. Esse fenômeno ocorre quando cristais de neve se depositam sobre uma camada com temperatura mais baixa. O gradiente térmico força o movimento das moléculas das camadas mais quentes para o ar frio acima da superfície. Assim, o vapor que se move através da neve se condensa nas superfícies dos grãos de gelo, o que produz cristais facetados e maiores. Tais camadas são conhecidas como hoar layers (camadas de escarcha) e são altamente porosas e de densidade muito baixa $\left(0,1\right.$ a $\left.0,3 \mathrm{~g} \mathrm{~cm}^{-3}\right)$. Quando esse tipo de feição se desenvolve em profundidade, a camada passa a ser classificada como depth hoar (escarcha de profundidade) (Cuffey \& Paterson, 2010).

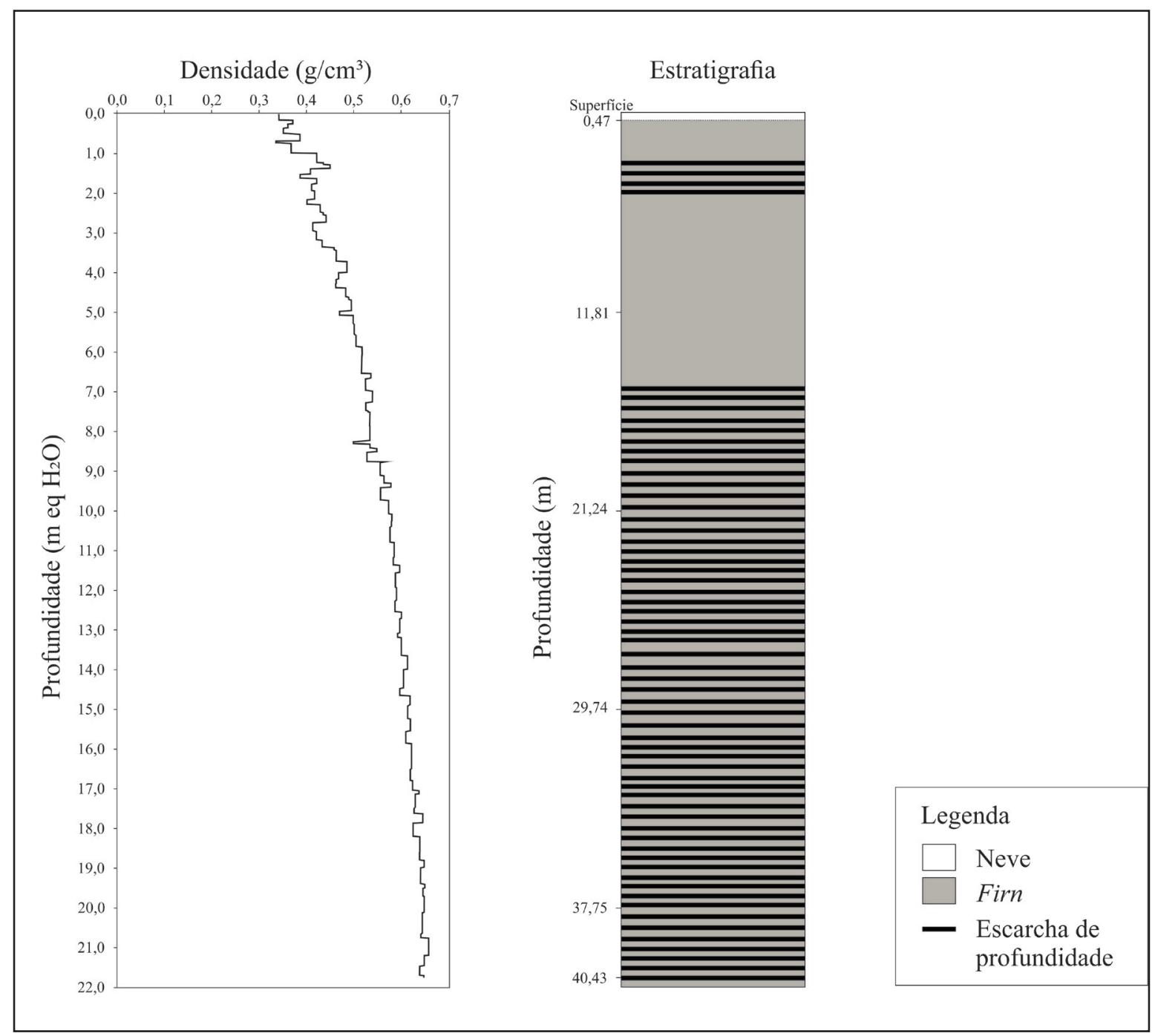

Figura 3. Perfis de densidade e estratigráfico do testemunho IC-02. Note que os estratos são constituídos basicamente de neve e firn, com intercalação de camadas de depth hoar (escarcha de profundidade).

Figure 3. IC-02 density and stratigraphic profiles. Note that strata are basically snow and firn, intercalated with depth hoar layers. 


\subsection{Intervalo dos dados e a relação $\delta^{18} O \times \delta D$}

A figura 4 apresenta a série isotópica $\left(\delta^{18} \mathrm{O}\right.$ e $\delta \mathrm{D})$ com todas as amostras do testemunho de gelo IC-02, de acordo com a profundidade em equivalente d'água. Como o testemunho foi coletado em duas partes (separadas em 0,5 m de distância na superfície), foi necessário fazer uma sobreposição vertical de 1,25 m entre os dados delas. Isto permitiu determinar a continuidade do registro baseando-se nas variações das razões isotópicas similares. No total, 1696 amostras foram usadas no estudo, equivalentes a 21,74 m equivalente d'água. As amostras do primeiro metro de testemunho da série de $\delta^{18} \mathrm{O}$ foram descartadas durante o descongelamento.

O $\delta^{18} \mathrm{O}$ no testemunho IC-2 tem uma média de $-46,39 \pm 1,37 \%$, variando entre $-50,77 \%$ e $-41,40 \%$. Já o $\delta \mathrm{D}$ médio é de $-367,43 \pm 12,51 \%$ e varia entre $-408,18 \%$ e $323,85 \%$. Note na figura 5 que a relação linear entre o $\delta \mathrm{D}$ e o $\delta^{18} \mathrm{O}$ $\left(\delta \mathrm{D}=8,28 \delta^{18} \mathrm{O}+17,73 ; \mathrm{R}^{2}=0,95\right)$ respeita a linha de Craig (1961) para água meteórica, o que seria de esperar, pois a estratigrafia do testemunho não apresenta sinais de processos pós-deposicionais (e.g., derretimento superficial da neve) que poderiam alterar a relação entre as duas razões isotópicas.

A figura 6 apresenta o mapa de distribuição espacial das razões de isótopos estáveis de amostras da Antártica (Masson-Delmotte et al., 2008). Comparando a média das duas razões isotópicas do $\mathrm{IC}-02,-46,38 \%$ para $\delta^{18} \mathrm{O}$ e $-367,43 \%$ para $\delta \mathrm{D}$, observa-se que estão de acordo com aquele estudo.

Nossos resultados também estão de acordo com as variações das razões isotópicas médias determinadas em uma trincheira na estação antártica Amundsen-Scott no Polo Sul geográfico por Mosley-Thompson et al. (1985), a $220 \mathrm{~km}$ de distância do IC-02. Esses autores encontraram o $\delta^{18} 0$ variando entre -56 e $-41 \%$.

\subsection{Datação do testemunho}

A cronologia dos testemunhos de gelo pode ser estabelecida pela contagem anual das camadas de gelo, porém essas são de difícil determinação onde não existe uma marcada sazonalidade de algum parâmetro físico (e.g., densidade da neve, conteúdo de micropartículas, formação de camadas de gelo no verão). Assim, adota-se em geral uma metodologia de multiparâmetros onde se examina independentemente a variabilidade sazonal, por exemplo, no conteúdo isotópico, concentrações iônicas ou de elementos-traço para determinar uma cronologia relativa. Já o uso de horizontes de referências, como picos de sulfato (determinados por cromatografia iônica) fornecem datas de erupções vulcânicas conhecidas e, portanto, uma datação absoluta (Brook, 2007).

A datação do testemunho IC-02 foi baseada na variação sazonal da razão de isótopos estáveis, corroborado pelas variações do conteúdo iônico de sódio $\left(\mathrm{Na}^{+}\right)$e sulfato de origem não marinha (nssSO ${ }_{4}^{-2}$, ou seja, no-sea salt sulphates) obtidos por cromatografia iônica. Os picos de $\delta \mathrm{D}$ e $\delta^{18} \mathrm{O}$ representam precipitações ocorridas durante os verões, quando então o fracionamento isotópico é menor do que no inverno (e o local de origem da massa de ar está mais perto devido à redução da cobertura de mar congelado ao redor do continente antártico). Ou seja, durante o verão a precipitação apresenta valores isotópicos mais positivos.

A interpretação do perfil dos dados isotópicos em conjunto com as variações de $\mathrm{Na}^{+}\left(\mu \mathrm{g} \mathrm{L}^{-1}\right)$ e nssSO ${ }_{4}^{-2}\left(\mu \mathrm{g} \mathrm{L}^{-1}\right)$ de 1091 amostras (14,35 $\mathrm{m}$ eq $\left.\mathrm{H}_{2} \mathrm{O}\right)$ do IC-02 fornecem uma idade equivalente a 85 anos (Fig. 7). De acordo com a datação estabelecida, o testemunho representa neve acumulada entre 1918 e 2003 (as amostras superficiais de 2004 foram descartadas). A datação estabelecida possui erro de aproximadamente 3 anos para mais ou para menos, devido aos anos incertos no registro, em que podem representar picos de verão ou ruídos da série de dados.

Alguns indícios nos valores de $\mathrm{nssSO}_{4}^{-2}$ corroboraram o resultado encontrado, como por exemplo, o pico no ano de 1993, o qual possivelmente representa a erupção vulcânica do monte Pinatubo (ilha Luzon, Filipinas) no ano de 1991 (observe que esse vulcão está no hemisfério norte, assim o transporte das impurezas deve ser 


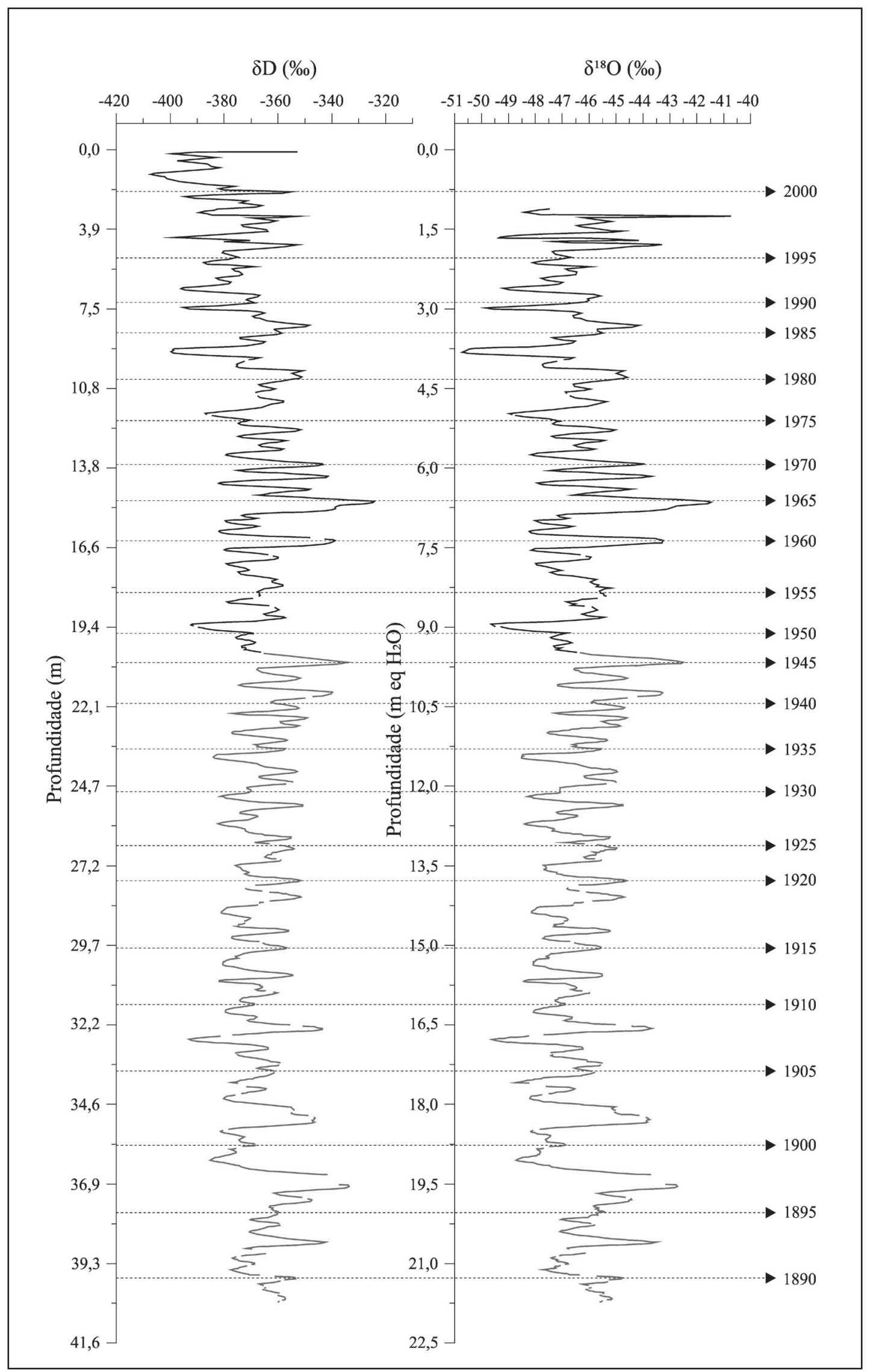

Figura 4. Perfis isotópicos, $\delta^{18} \mathrm{O}$ e $\delta \mathrm{D}$, profundidade em $\mathrm{m}$ eq $\mathrm{H}_{2} \mathrm{O}$. A linha preta do gráfico representa a parte superior do testemunho de firn (seção 22A). A linha cinza no gráfico representa o segundo testemunho (22B), perfurado a 0,5 m de distância do primeiro.

Figure 4. Stable isotopic profiles, $\delta^{18} \mathrm{O}$ and $\delta D$, depth in $\mathrm{m}$ eq $\mathrm{H}_{2} \mathrm{O}$. The black line in the graph represents the upper part of the firn core (22A), while the gray line represents the second core (22B), drilled $0.5 \mathrm{~m}$ apart of the first one. 


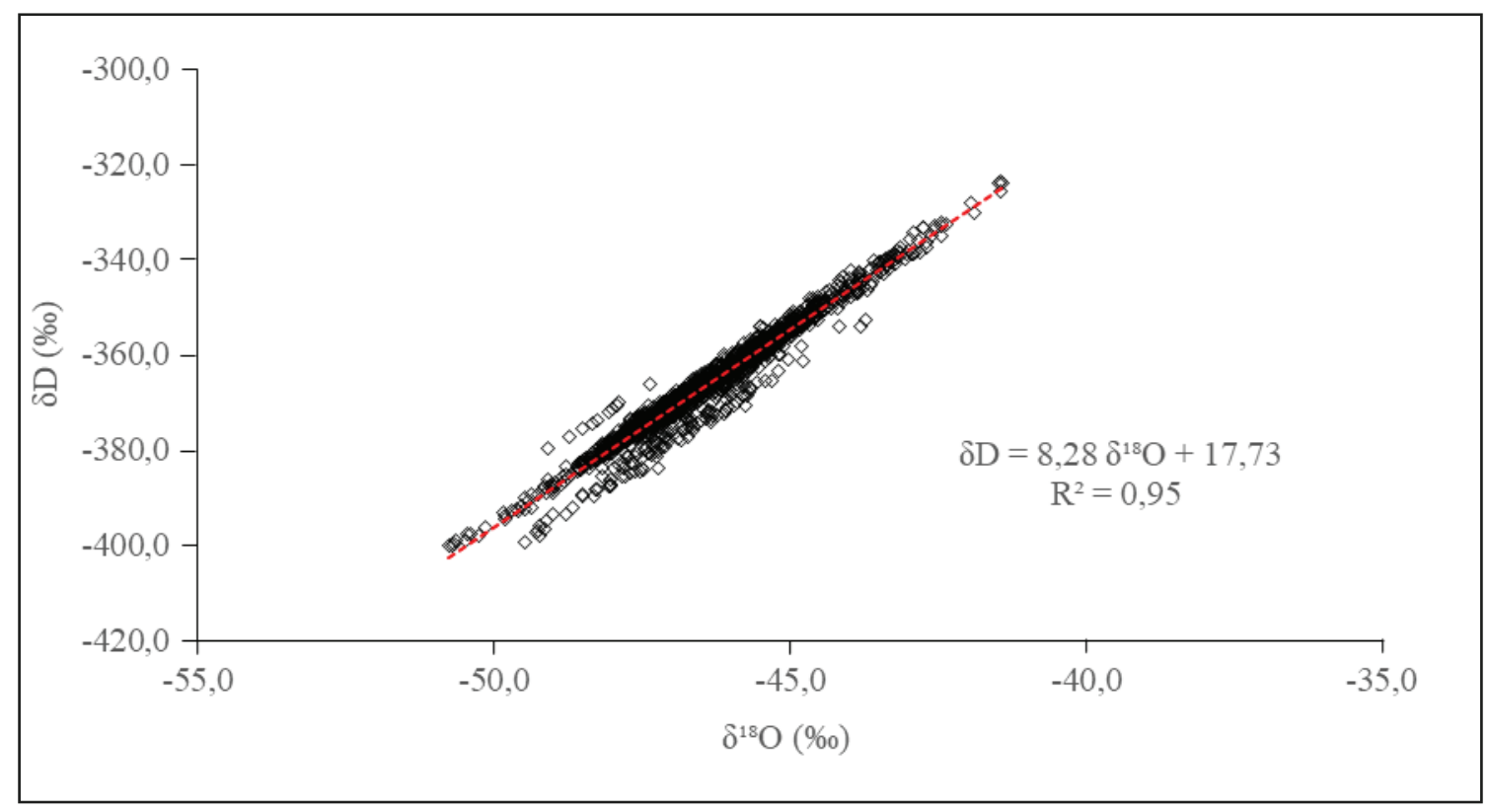

Figura 5. Gráfico mostrando a relação linear entre $\delta D$ e $\delta^{18} 0$ no testemunho de firn. A equação da reta respeita a linha de água meteórica (Craig, 1961).

Figure 5. Graphic showing the liner relation between $\delta D$ e $\delta^{18} \mathrm{O}$ in the firn core. The line equation agrees with the meteoric water line (Craig, 1961).

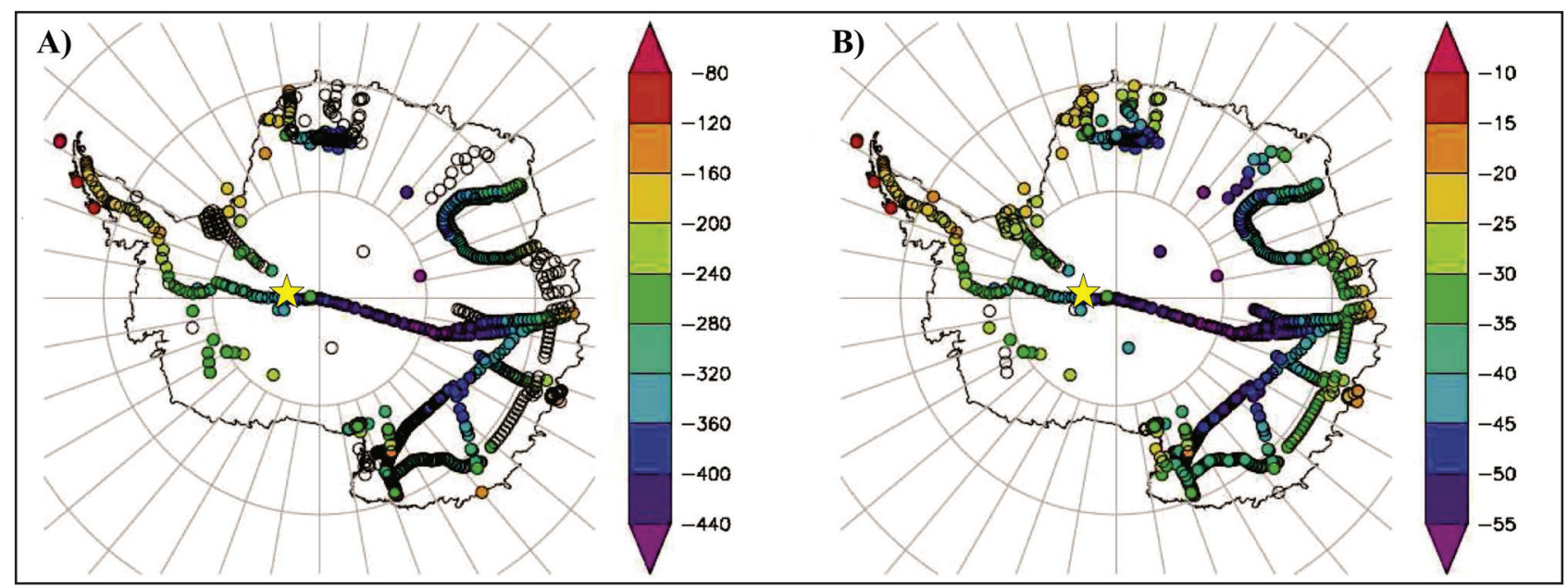

Figura 6. Mapa da Antártica mostrando a distribuição das razões de isótopos estáveis. A) $\delta \mathrm{D}(\%)$; B) $\delta^{18} \mathrm{O}(\%)$. As estrelas em amarelo nos dois mapas representam a localização do IC-02. Modificado de Masson-Delmotte et al. (2008).

Figure 6. Antarctic map showing stable isotope ratios distribution: (a) $\delta D(\%)$, (b) $\delta^{18} O(\%)$. The yellow stars on both maps represent the location of the IC-02. Modified from Masson-Delmotte et al. (2008).

estratosférico, podendo tomar até 2 anos para chegar na Antártica). Outro pico de $\mathrm{nssSO}_{4}^{-2}$ é atribuído a erupção do monte Agung em 1963, em Bali na Indonésia, portanto marca o ano de 1965. De acordo com a interpretação de toda a série isotópica do IC-02, as 1755 amostras (21,74 $\mathrm{m}$ eq $\mathrm{H}_{2} \mathrm{O}$ ) alcançam o ano de 1890, o que equivale a 113 anos de registro paleoclimático (Fig. 4). Em razão da menor quantidade de dados químicos disponíveis para essa datação, o intervalo considerado nas discussões das séries temporais foi o de 1918-2003, em termos de variações climáticas.

Vale ressaltar que a interpretação dos três primeiros picos significativos no perfil iônico do $\mathrm{nnSO}_{4}{ }^{2-}$ descartam a possibilidade de contaminação do testemunho pois o aumento da concentração ocorre de forma gradativa no perfil estratigráfico. A explicação para tal ocorrência poderia estar relacionado com a erupção de Bristol Island, na Antártica, no ano de 1936. 


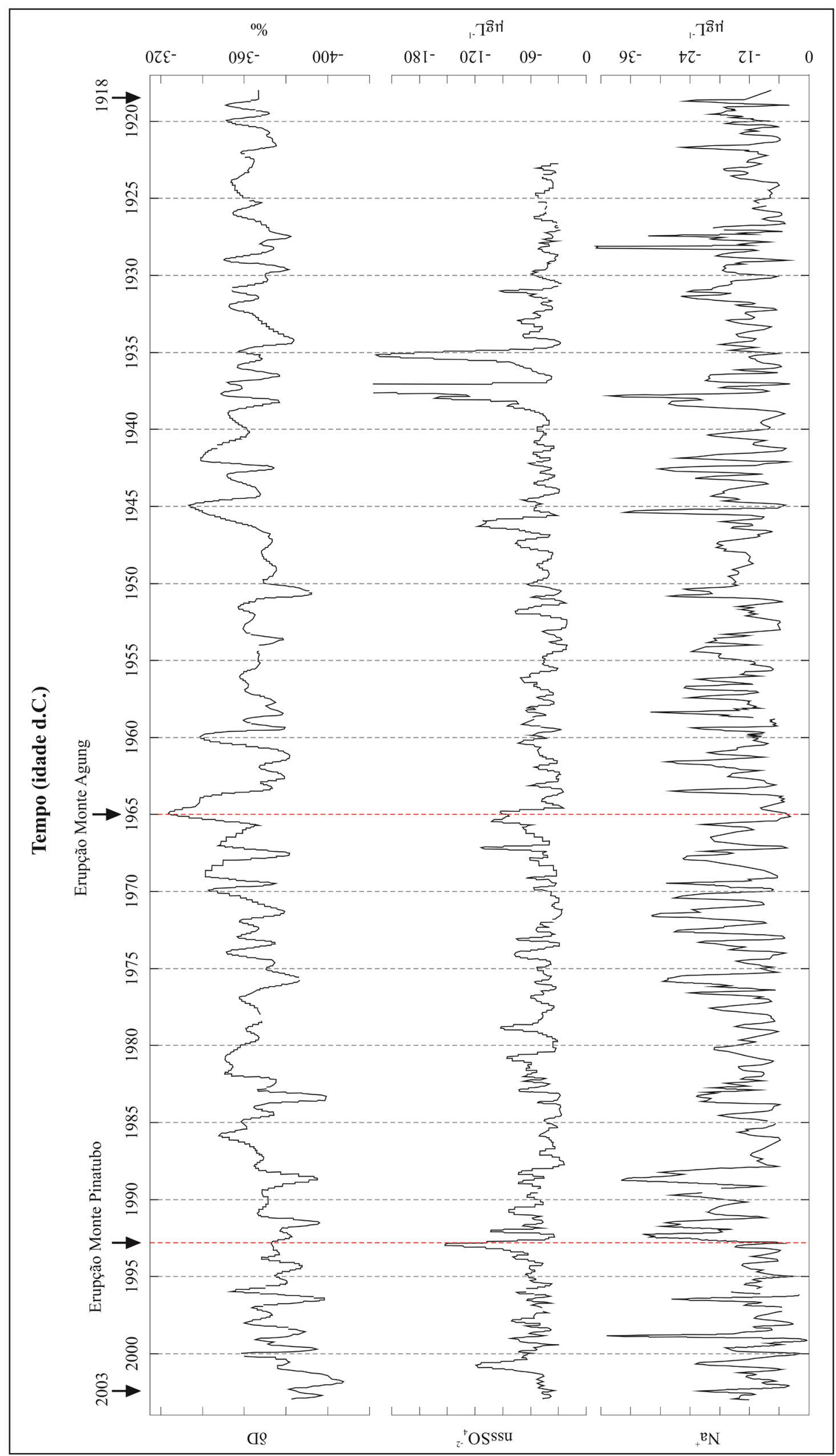

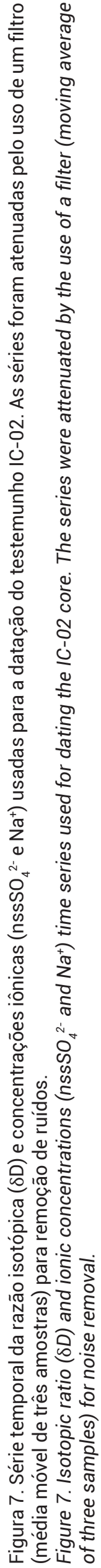




\section{Discussão dos resultados}

\subsection{Fatores controladores da distribuição espacial de $\delta D$ e $\delta^{18} \mathrm{O}$}

Dansgaard (1964) foi pioneiro em sumarizar os fatores que controlam o comportamento e distribuição dos isótopos estáveis na precipitação, como o efeito da temperatura, da latitude, da altitude, da continentalidade e da origem da precipitação. Craig (1961) já apontava que a temperatura do ar é o principal fator em médias e altas latitudes, principalmente em regiões polares. Masson-Delmotte et al. (2008) compilaram um dos mais completos banco de dados isotópicos $\left(\delta^{18} \mathrm{O}\right.$ e $\left.\delta \mathrm{D}\right)$ e confirmaram que a distribuição espacial das razões isotópicas na Antártica é fortemente associada com a temperatura de condensação, que por sua vez é controlada por parâmetros geográficos (distância da costa, latitude e elevação).

O que ocorre é que a água que evapora dos oceanos nos subtrópicos, além da umidade vinda dos continentes e oceanos polares, move-se em direção aos polos, e devido ao resfriamento dessa massa de ar, ocorre a condensação e precipitação (Fig. 8). Os isótopos pesados são preferencialmente extraídos do vapor d'água pela condensação para formar gotículas líquidas ou partículas de gelo. Dessa maneira, o vapor d'água restante, assim como a precipitação provinda dele, torna-se isotopicamente mais leve com o aumento da distância ao longo da trajetória. Em decorrência disso, a neve acumulada nas camadas de gelo é mais leve que a fonte oceânica original. Durante o decorrer do fenômeno descrito, os fatores controladores da distribuição espacial atuam sobre a variação isotópica, conforme discutido no tópico seguinte.

\subsubsection{Fatores geográficos}

A série isotópica $\left(\delta^{18} \mathrm{O}\right.$ e $\left.\delta \mathrm{D}\right)$ apresentada na figura 4 corrobora as hipóteses levantadas por outros autores, no qual a continentalidade ou a distância do local de perfuração do testemunho até a costa, assim como, a latitude e a elevação, controlam a distribuição dos isótopos estáveis. Todos esses efeitos atuantes no fracionamento isotópico do oxigênio e deutério ocorrem devido à remoção preferencial dos isótopos pesados durante o evento de precipitação, o que resulta em nuvens carregadas em isótopos leves avançando para latitudes mais altas, ou para o interior do continente ou para altas altitudes.

Marquetto et al. (2015) analisaram a composição isotópica de oxigênio na neve superficial coletada ao longo da mesma travessia antártica em que se obteve o testemunho IC-02. O valor médio de $\delta^{18} \mathrm{O}$ do IC-02 é de $-46,42 \%$, o qual se encontra no mesmo sítio de amostragem da neve superficial analisada por Marquetto et al. (2015) que obteviram $-49,1 \%$, valor relativo ao inverno de 2004.

O local de perfuração do IC-02 está a $1.967 \mathrm{~km}$ de distância da costa, numa altitude de $2.621 \mathrm{~m}$. Amostras analisadas por Marquetto et al. (2015) que estão em regiões mais próximas à costa possuem $\delta^{18} \mathrm{O}$ entre -35 a $-31 \%$ numa altitude de $1.531 \mathrm{~m}$, enquanto próximo ao Polo Sul geográfico as razões chegam a aproximadamente $-52 \%$ na altitude de $2.833 \mathrm{~m}$, numa distância de $2.110 \mathrm{~km}$ da costa. Com isso, fica claro que fatores geográficos controlam a distribuição espacial dos isótopos estáveis da precipitação na região de estudo. Ressalta-se que todos os fatores (continentalidade, latitude e elevação) atuam ao mesmo tempo em que a massa de umidade permanece em circulação, e que, portanto, quanto maior a trajetória da massa, mais pobre em isótopos pesados ela será.

\subsection{Análise das séries temporais $\delta^{18} \mathrm{O}$ e $\delta D$}

\subsection{Determinação da taxa anual de acumulação de neve entre 1918 e 2003}

A forma direta de se obter a variabilidade da taxa de acumulação anual de neve é pela identificação de sucessivas camadas, que pode ser feita por várias abordagens, como inspeção visual e composição química. Neste caso específico, a taxa de acumulação foi determinada a partir da datação estabelecida com base na sazonalidade dos elementos químicos.

A média da acumulação líquida anual no IC-02 é $152 \pm 64 \mathrm{~mm}$ ano $^{-1}$ em equivalente d'água. Este é um valor esperado de acumulação nesta 


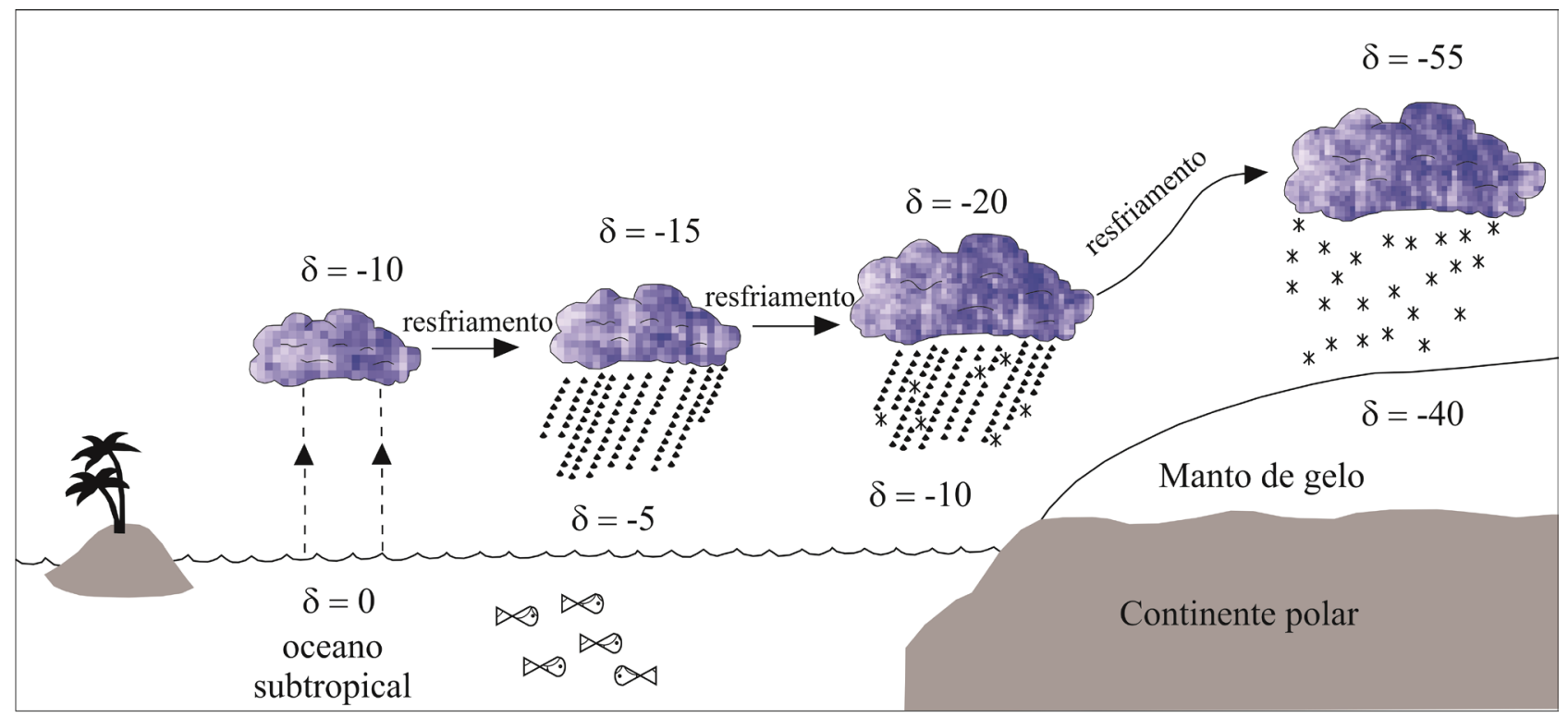

Figura 8. Modelo de transporte da umidade formada em latitudes médias e altas, com ênfase na variância das razões isotópicas $(\delta)$ nas massas de ar e precipitação. Fonte: Cuffey \& Paterson (2010).

Figure 8. Model for the transport of moisture formed at medium and high latitudes, with emphasis on the variance of isotopic ratios $(\delta)$ in air masses and precipitation. Source: Cuffey \& Paterson (2010).

parte do platô do manto de gelo conforme Veen et al. (1999) e Masson-Delmotte et al. (2008), consequência da continentalidade e altitude do sítio, o que resulta em uma baixa umidade que por sua vez gera baixa precipitação.

O valor máximo de acumulação de 292 mm ocorreu em 1959 e o valor mínimo de 27 mm em 1968 (Fig. 9). Apesar dos dados mostrarem haver uma variabilidade natural na acumulação de neve para esse sítio, nota-se a ocorrência de alguns anos com valores bem acima da média (> $200 \mathrm{~mm}$ ano-1), quais sejam: 1919, 1927, 1929, 1936, 1942, 1950, 1953, 1958, 1959, 1969, 1982, 1983, 1991, 1995, 1996, 1998, 1999, 2001 e 2002.

O ano de 1919 apresentou uma taxa de acumulação de $291 \mathrm{~mm}^{2} \mathrm{ano}^{-1}$, enquanto o ano 1924, a acumulação alcançou apenas 55 mm $a^{n} o^{-1}$, o que mostra a grande variação de ano para ano. A média da acumulação líquida nos últimos 30 anos (1974-2003) aumentou em 17\% quando comparado ao período anterior (1944-1973), de $136,3 \pm 58,4 \mathrm{~mm}$ eq $\mathrm{H}_{2} \mathrm{O}$ para $164,7 \pm 64,5 \mathrm{~mm}$ eq $\mathrm{H}_{2} \mathrm{O}$. Mosley-Thompson et al. (1999) observaram mudança similar na acumulação líquida média anual no Polo Sul geográfico, onde essa taxa aumentou 30\% desde a década de 1960.

Pesquisas mais recentes, por Turner et al. (2019), indicam que a quantidade de neve que precipita na Antártica é muito variável e depende das condições meteorológicas sobre o oceano Antártico e a penetração de ar marinho no interior do continente. Em todo continente, os eventos extremos de precipitação (EEP) são os principais controladores da variabilidade anual de precipitação de neve. Normalmente, os episódios de precipitação no platô Antártico ocorrem com céu claro, quase que continuamente, mas também existem eventos extremos quando ocorrem rápidas intrusões de ar de origem da evaporação marítima, através de faixas estreitas de umidade, conhecidas como "rios atmosféricos". Os EEP são os principais responsáveis por quantidades relativamente altas de precipitação no interior da Antártica (Genthon et al., 1998), sendo considerados aqueles que ocorrem no período de um ou mais dias consecutivos, quando a precipitação diária é maior que 90\% dos valores diários de toda a série temporal. A pesquisa de Turner et al. (2019) foi baseada em dados diários de precipitação total que excediam 0,02 mm, que apesar de ser um número muito baixo para regiões polares, esse valor deve ser considerado quando analisa-se locais no alto platô Antártico (Bromwich, 1988; Zhu \& Newell, 1998; Turner et al., 2019).

Importante ressaltar é que a evaporação é praticamente nula durante o inverno em locais 


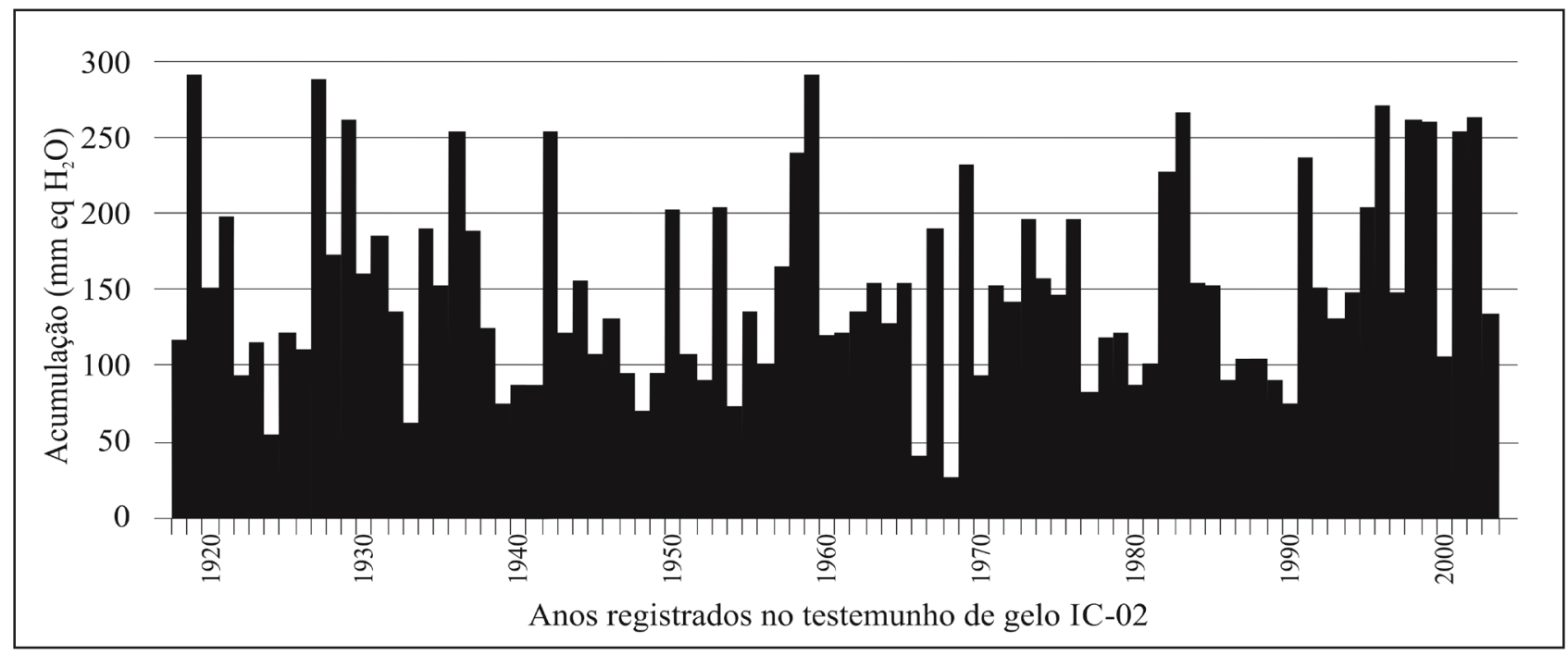

Figura 9. Taxa média de acumulação líquida anual de neve (1918-2003) no platô Antártico. Figure 9. Mean annual snow net accumulation rate (1918-2003) in the Antarctic plateau.

longe da costa (Grieger, 2016). A ação dos ventos pode remover ou adicionar localmente a neve precipitada, afetando assim a quantidade de neve em alguns locais, principalmente próximo a vales glaciais íngremes. Além disso, durante o inverno, a atividade ciclônica é muito maior do que no verão em que os eventos extremos de precipitação têm influência menor sobre o oceano e as áreas costeiras (Turner et al., 2019).

\subsubsection{Variações das razões isotópicas entre 1918 e 2003}

\section{Variações de $\delta D$ e $\delta^{18} O$}

Além do ciclo sazonal, ou seja, a variação verão-inverno nas duas razões isotópicas ( $\delta \mathrm{D}$ e $\delta^{18} 0$ ) na precipitação, não é evidente outro padrão de variação. A baixa taxa de acumulação de neve no platô Antártico, principalmente quando comparado ao Ártico, torna mais difícil o registro de outras variações de curto-prazo, como a da atividade solar, correlacionada a um ciclo de 11 anos (Raisbeck et al., 1990).

No entanto, os dados apontam uma tendência de aumento da depleção dos isótopos pesados na precipitação ao longo do período de estudo. No gráfico da figura 10, as médias anuais dos valores de $\delta \mathrm{D}$ foram representadas de acordo com o ano de precipitação da amostra, sendo evidente a tendência de redução das razões isotópicas a partir da década de 1990, isto é, os valores de $\delta \mathrm{D}$ passam a ser cada vez mais negativos. Neste caso, o $R^{2}=0,1526$ é estatisticamente significante com $\alpha<0,005$.

Contudo, o período 1990-2003, que realmente mostra material isotopicamente mais leve, não oferece segurança na análise estatística, pois algumas das amostras correspondentes a esse momento (85 amostras) só foram analisadas para $\delta \mathrm{D}$, e isso faz com que seja impossível saber se os valores obedecem à linha de água meteórica de Craig (1961).

\section{Variações no excesso de deutério $(d)$}

Como as duas razões de isótopos estáveis foram medidas de forma contínua no testemunho IC-02 a partir dos $3 \mathrm{~m}$ de profundidade $(1,1 \mathrm{~m}$ em equivalente d'água), foi possível calcular o excesso de deutério (d) para todas as amostras $\left(d=\delta D-8 \delta^{18} 0\right)$ e examinar sua variação no período 1918-1998. Esse parâmetro serve de indicador das condições (principalmente temperatura) e variabilidade climática na área fonte da precipitação, e ajuda na calibração da relação razão isotópica-temperatura (Brook, 2007).

O gráfico da figura 11 mostra a variação do excesso de deutério com a profundidade 


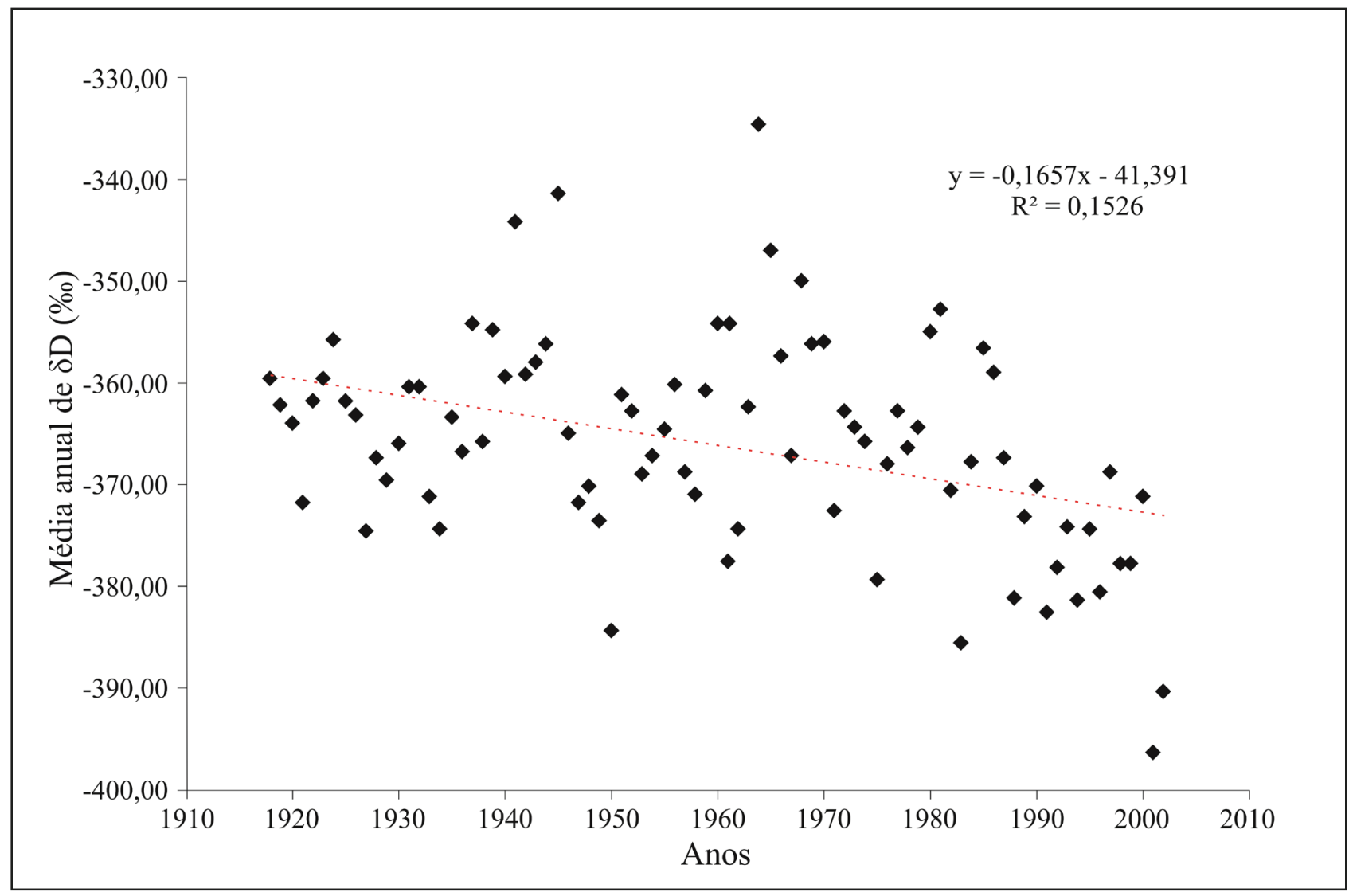

Figura 10. Média anual do $\delta \mathrm{D}(\%)$ na precipitação no testemunho de firn IC-02. A linha tracejada mostra a tendência de redução na razão isotópica.

Figure 10. Mean annual $\delta D(\%)$ in the IC-02 firn core. The dashed line shows the trend of reduction in the isotopic ratio.

(em m eq. $\mathrm{H}_{2} \mathrm{O}$ ) no IC-02. O valor médio é de $4,36 \pm 2,66 \%$, mas apresenta variabilidade anual. Nos $3 \mathrm{~m}$ superiores do testemunho, o valor médio está em patamar reduzido (somente $1,95 \pm 1,40 \%$ ). Essa diferença bem marcada nos primeiros metros do $1 \mathrm{C}-02$ são referentes às 200 primeiras amostras que foram analisadas separadamente em um espectrômetro de massa com fonte de gás (GSMS - Gas Source Mass Spectrometry) no Climate Change Institute (Universidade do Maine, EUA). O modelo de fracionamento isotópico não reproduz o fracionamento simultâneo de $D$ e ${ }^{18} 0$, pois as três moléculas isotópicas $\left(\mathrm{H}_{2}{ }^{16} \mathrm{O}, \mathrm{HD}^{16} \mathrm{O}\right.$ e $\left.\mathrm{H}_{2}{ }^{18} \mathrm{O}\right)$ não tem a mesma difusividade no vapor d'água da atmosfera (Merlivat, 1978), explicado através da microfísica de fracionamento isotópico.

De acordo com Vimeux et al. (2001), a rápida flutuação nos valores em d pode refletir variações climáticas ou resultar de processos deposicionais e pós-deposicionais. A alta variabilidade nesse registro pode ser resultado de mudanças nas áreas fontes da precipitação, efeitos no momento da deposição da neve (erosão pelo vento, microtopografia da superfície) e efeitos pós-deposicionais (sublimação no verão e formação de depth hoar) reforçada pela baixa taxa de acumulação anual da precipitação.

Conforme observado no perfil estratigráfico do IC-02, camadas com formação de depth hoar são frequentes em todo o testemunho. Além disso, a baixa taxa de acumulação também corrobora para a variabilidade dos valores do excesso de deutério. Mais análises são requeridas para determinar a causa dessas variações, como a modelagem atmosférica das massas de ar que chegam ao sítio de coleta do testemunho.

A distribuição espacial do excesso de deutério na neve e gelo do continente antártico mostra distinta diferença entre as regiões perto da costa (e abaixo de $2.000 \mathrm{~m}$ de altitude) daquelas do interior antártico e acima dos $2.000 \mathrm{~m}$. Conforme se afasta da costa, em geral, bem maiores serão os valores de d, principalmente no platô da Antártica Oriental (Vimeux et al., 1999; Masson-Delmotte et al., 2008). Esse aumento 


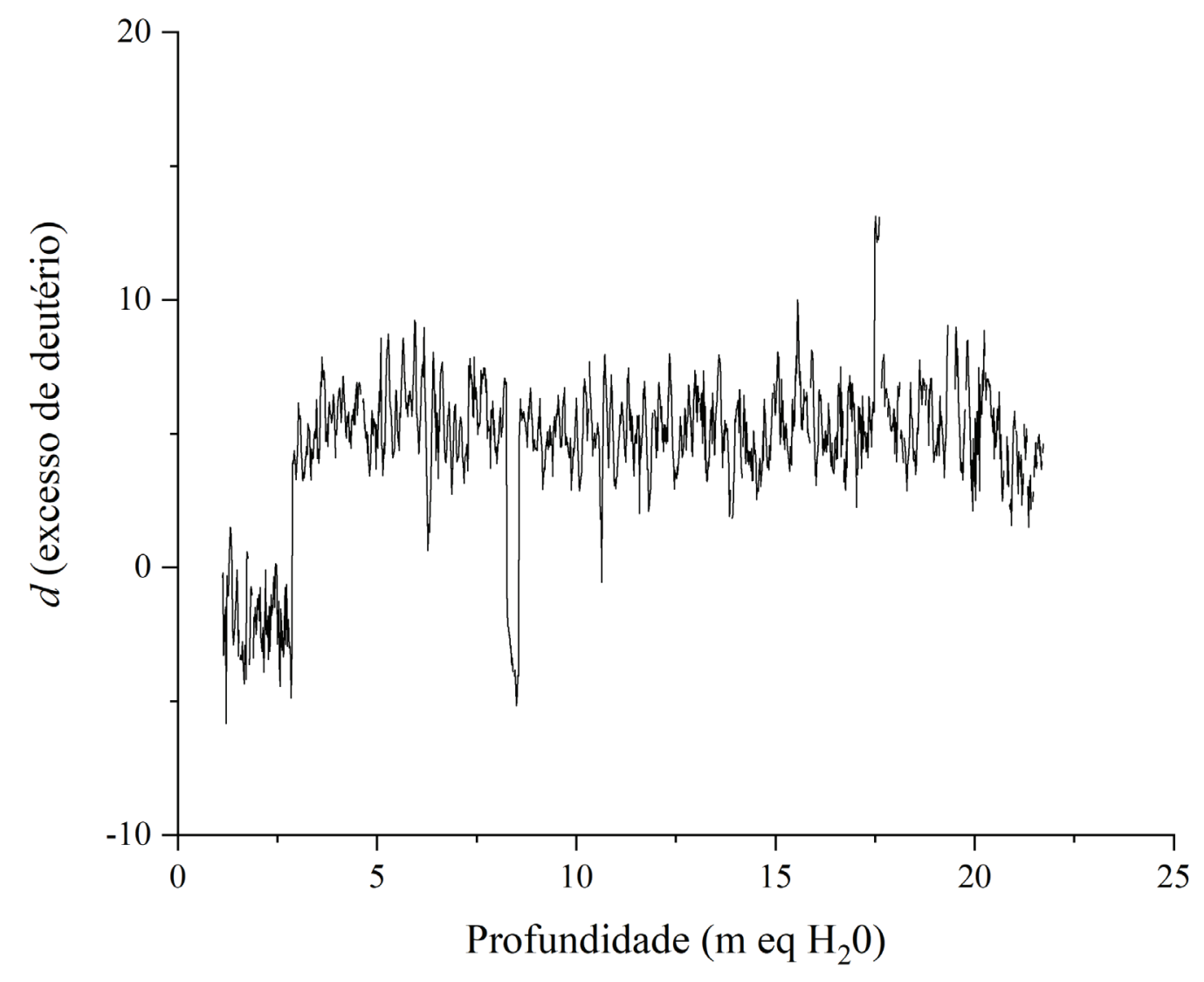

Figura 11. A variação do excesso de deutério (d) com a profundidade (em m eq. $\mathrm{H}_{2} \mathrm{O}$ ) no testemunho IC-02. Figure 11. The excess deuterium (d) variation in depth (in $\mathrm{m}$ eq. $\mathrm{H}_{2} \mathrm{O}$ ) in the IC-02 core.

no d continental é relacionado à temperatura atmosférica. Gradualmente a água condensada sofre um desvio da linha d'água meteórica (calculada na escala global, na qual um coeficiente de 8 resulta dos coeficientes médios de fracionamento em equilíbrio), com a redução da temperatura de condensação. Em outras palavras, o excesso de deutério aumenta para o interior do continente antártico, diminuindo a inclinação da reta na relação $\delta^{18} 0-\delta \mathrm{D}$ (Vimeux et al., 1999; Masson-Delmotte et al., 2008; Touzeau et al., 2016).

4.2.3 A relação entre as razões isotópicas com a taxa de acumulação e a temperatura atmosférica superficial

Existe uma relação estatisticamente significante entre a variação na taxa de acumulação, calculada no tópico anterior, e a variação de $\delta \mathrm{D}$. De acordo com o gráfico da correlação entre essas duas variáveis (Fig. 12A), desde 1918, apresenta $R^{2}=0,1818$, com $\alpha<0,005$. Quando a análise é feita desde 1957, o $R^{2}=0,2336(\alpha<0,005)$ mostra que existe uma clara tendência de diminuição do $\delta \mathrm{D}$ (Fig. 12B).

As variações espaciais de $\delta D$ estão fortemente relacionadas com as variações espaciais da temperatura, que por sua vez estão conectadas com a distância do oceano aberto ("efeito de continentalidade"), latitude (relacionado à insolação), elevação (efeito da diferença de altitude) e circulação atmosférica (penetração de sistemas ciclônicos sinóticos). O banco de dados, compilado por MassonDelmotte et al. (2008), em que foram usadas estações meteorológicas automáticas (sigla em inglês AWS) ou medições de temperatura do firn, forneceu um gradiente de temperatura espacial de $-11,4^{\circ} \pm 0,2{ }^{\circ} \mathrm{C}(1000 \mathrm{~m})^{-1}$ de elevação, juntamente com uma diminuição da temperatura de $-27,8 \pm 0,9{ }^{\circ} \mathrm{C}(1000 \mathrm{~km})^{-1}$ desde a costa. A variação da temperatura superficial em relação à elevação está entre $9^{\circ}$ (áreas costeiras) e $12{ }^{\circ} \mathrm{C}(1000 \mathrm{~m})^{-1}$ (regiões do platô antártico). Um fator importante é que o sítio de perfuração do 


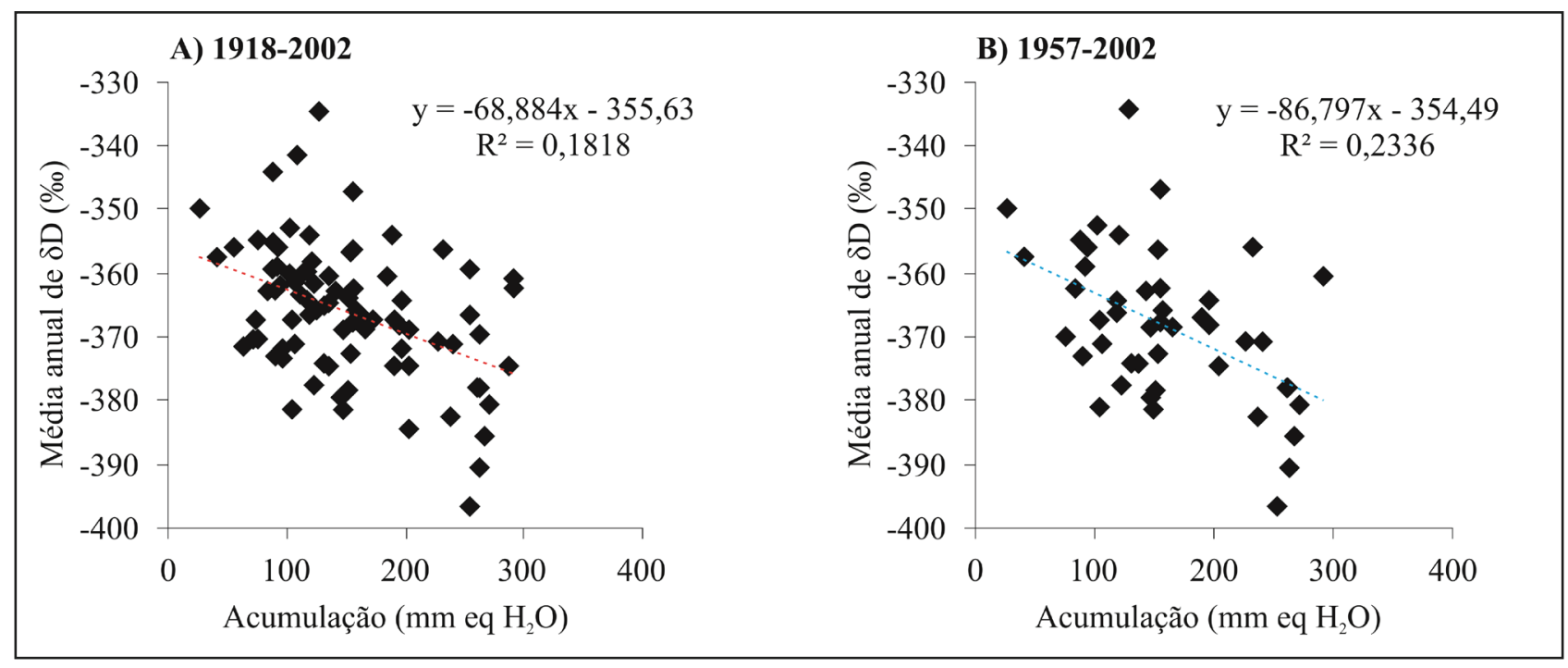

Figura 12. Variação da taxa anual de acumulação de neve (em m eq. $\mathrm{H}_{2} \mathrm{O}$ ) com a média anual de $\delta \mathrm{D}(\%)$ no testemunho IC-02. A) Desde o ano de 1918; B) A mesma comparação, mas somente desde o ano de 1957.

Figure 12. Accumulation rate variation (in $\mathrm{m}$ eq. $\mathrm{H}_{2} \mathrm{O}$ ) with the mean annual $\delta D(\%)$ in the IC-02 core. A) Since 1918; B) The same comparison but only since 1957.

IC-02 está a $2.621 \mathrm{~m}$ de altitude, numa latitude de $88^{\circ} 01^{\prime} 21,3^{\prime \prime} \mathrm{S}$ e $82^{\circ} 04^{\prime} 21,7^{\prime \prime} \mathrm{W}$, ou seja, mais frio e longe da costa, resultando em um maior fracionamento isotópico.

As séries de $\delta \mathrm{D}$ e $\delta^{18} \mathrm{O}$ apresentam o efeito sazonal, em que variam de acordo com o período de verão e inverno. Os valores mais baixos das razões isotópicas marcam o inverno, enquanto as razões mais elevadas são os picos de verão, devido ao grande resfriamento que ocorre no inverno em regiões polares, muito diferente das áreas fonte de baixa latitude do vapor atmosférico. Logo, a temperatura atmosférica influencia diretamente no fracionamento isotópico da massa de ar, além de todos os outros fatores geográficos explicados anteriormente (Dansgaard et al., 1973).

A relação direta entre a taxa de acumulação do testemunho IC-02 e a temperatura atmosférica superficial (medida na estação meteorológica do Polo Sul geográfico), corrigida em uma redução de $4,5^{\circ} \mathrm{C}$ para o sítio do IC-02, é ausente de significância estatística, com $\alpha>0,005$, o que impossibilita o cálculo de uma equação de transferência.

\subsection{Interpretação ambiental}

O significado da redução de $\delta \mathrm{D}$, a partir de 1957, indica tendência a um maior resfriamento durante o caminho percorrido pela massa de ar dentro do continente antártico até o local de precipitação. Isso, somado ao aumento na precipitação, está relacionado com determinados fenômenos atmosféricos. Mas, contrário ao esperado, não existe uma relação estatística significante entre a temperatura e o $\delta \mathrm{D}$.

Desde 1957 até 1982, de acordo com os dados do ADD (2019: Antarctic Digital Database - SCAR), a variação da temperatura atmosférica na estação Amundsen-Scott apresentou pequena amplitude (Fig. 13A). A partir de 1983, existe uma mudança na amplitude interanual, em que a temperatura alcança valores mais baixos (Fig. 13A). O gráfico (Fig. 13A) mostra uma tendência de aumento da temperatura após o ano 2003. Quando os dois períodos são desmembrados, conforme a figura 13B, é possível observar a mudança na linha de tendência dos valores, a qual é estatisticamente significante $\operatorname{com} \alpha<0,005$.

Os dados de reanálise NCEP/NCAR, calculados e disponibilizados no site da NOAA ESRL Physical Sciences Division (PSD), da temperatura média do continente antártico foram compilados e são representados nas figuras 14 e 15. A uma pressão de 500 mb, as imagens mostram como ocorreu a variação na temperatura média do ar ao lado da modificação da anomalia. É possível observar uma mudança de comportamento quando comparado os dados do período de 1957-2003 aos dados de 20042018. 


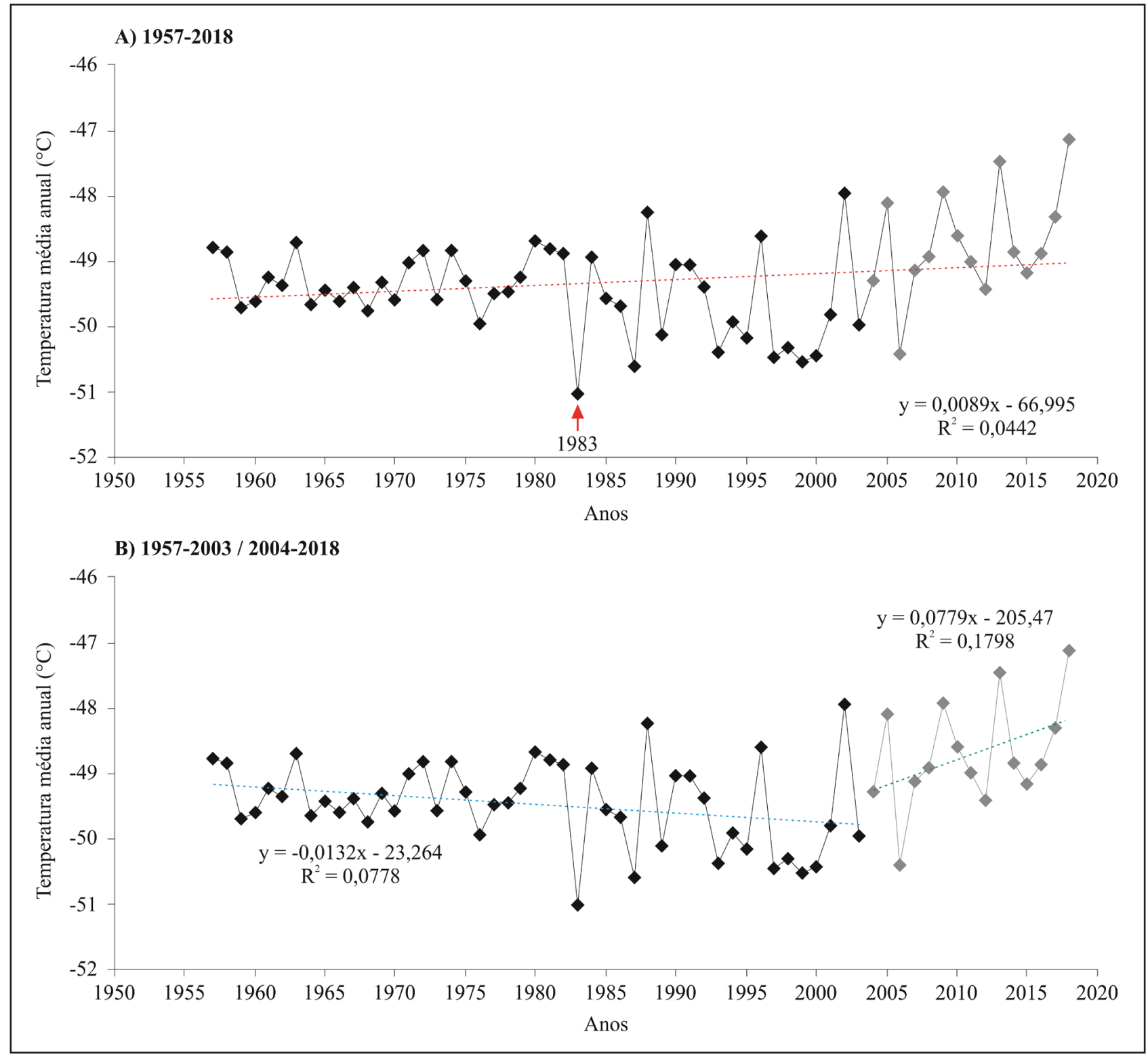

Figura 13. Variação da temperatura média anual do Polo Sul geográfico (Fonte: SCAR). A) 1957 até 2018 ; B) 1957 até 2003 e de 2004 a 2018. Em B é possível observar a tendência de esfriamento até 2003 e de aquecimento desde então. Figure 13. Mean annual temperature variation at the Geographical South Pole (Source: SCAR). A) from 1957 to 2018; B) from 1957 to 2003 and from 2004 to 2018. In B) it is possible to observe the cooling trend until 2003 and warming since then.

A anomalia da temperatura (reanálise da NOAA nas Fig. 14 e Fig. 15) indica um resfriamento para a região do sítio de perfuração do IC-02, no período 1957-2003 (Fig. 14). Dessa maneira, as razões isotópicas do IC-02, cada vez mais negativas a partir da década de 1957, resultam do esfriamento de grande parte do interior do continente antártico (Fig. 14).

A partir do início da década de 2000, a anomalia da temperatura atmosférica muda o padrão de comportamento (Fig. 15B), indicando um aumento da temperatura sobre o continente antártico. A análise do período pós-2003 não engloba os dados isotópicos do IC-02, pois esse testemunho foi obtido em 2004.

Tal comportamento concorda com observações de Gong \& Wang (1999), Kidson (1999), Sexton (2001), Polvani \& Kushner (2002), Thompson \& Solomon (2002), Marshall (2003), Karpetchko et al. (2005), que afirmam que tais modificações resultam de mudanças na intensidade do vórtice polar estratosférico desde meados da década de 1970, impulsionadas pelo esfriamento da baixa estratosfera antártica induzida principalmente pelas perdas fotoquímicas do ozônio. Basicamente, trata-se da 
variabilidade do SAM (Southern Annular Mode), ou modo anular do Hemisfério Sul (HS), um padrão de variabilidade na circulação atmosférica em grande escala, marcado por uma diferença zonal da pressão atmosférica entre as latitudes $40^{\circ} \mathrm{S}$ e $65^{\circ} \mathrm{S}$ (Turner \& Marshall, 2011). 0 vórtice polar é uma característica distinta da circulação estratosférica no inverno nos hemisférios norte e sul, o qual compreende uma forte circulação circumpolar horária no hemisfério sul, isolando a estratosfera polar, e aproximadamente centrado sobre o Polo Sul geográfico (Karpetchko et al., 2005). Dessa maneira, a mudança em alguns processos que interferem com o SAM, afeta o clima da Antártica. Thompson \& Solomon (2002) e Marshall (2003) relatam que o SAM tendeu a estar na sua fase positiva desde meados de 1970 e continua até o presente.

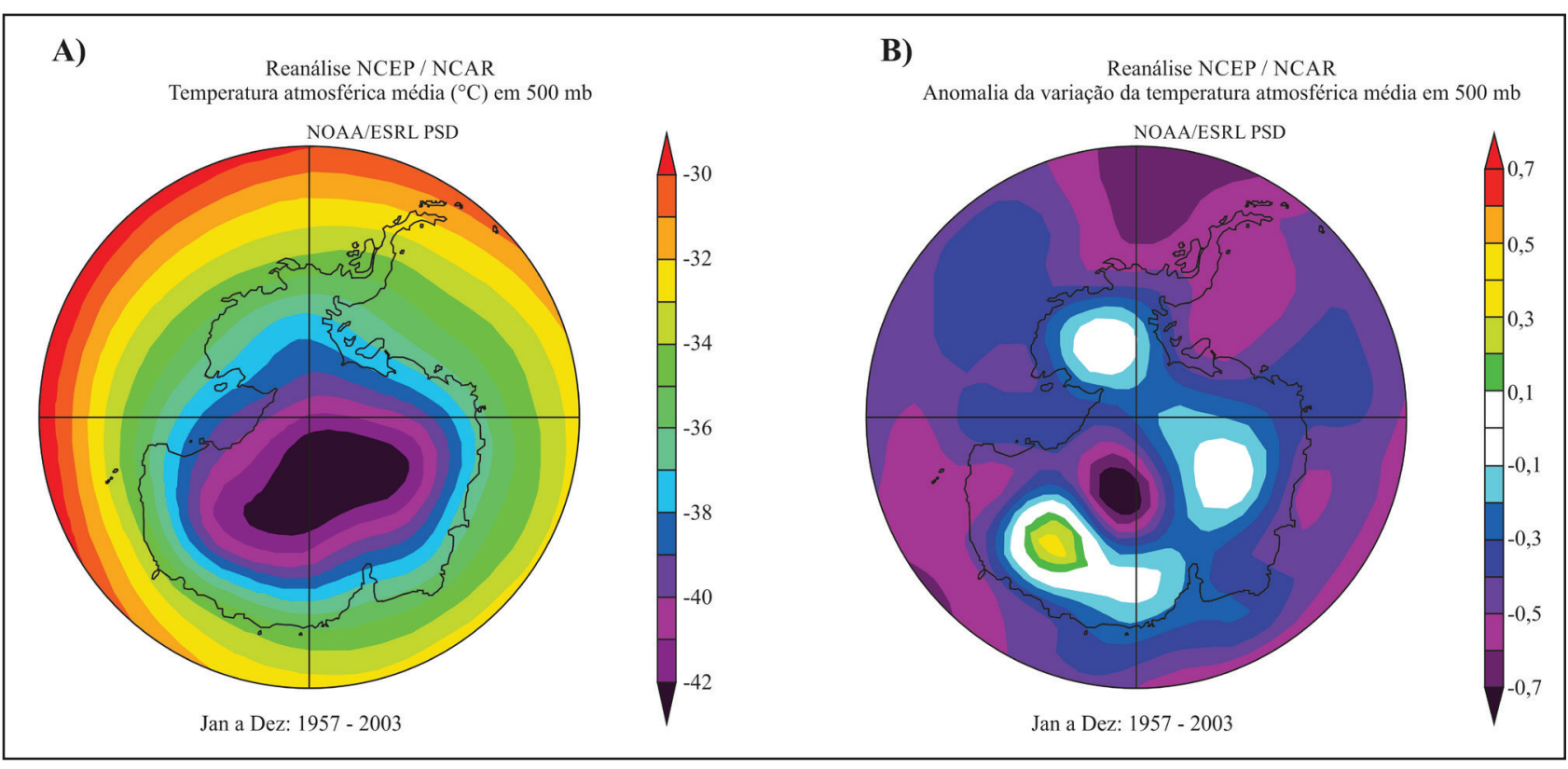

Figura 14. Dados de reanálise NCEP/NCAR para o período 1957-2003. A) Temperatura atmosférica média ( $\left.{ }^{\circ} \mathrm{C}\right)$ em $500 \mathrm{mb}$; B) Anomalia dessa variação, também em 500 mb (fonte: NOAA ESRL PSD).

Figure 14. NCEP / NCAR reanalysis data for the 1957-2003 period. A) The mean atmospheric temperature $\left({ }^{\circ} \mathrm{C}\right)$ in $500 \mathrm{mb}$; B) The anomaly of this variation also in $500 \mathrm{mb}$ (source: NOAA ESRL PSD).

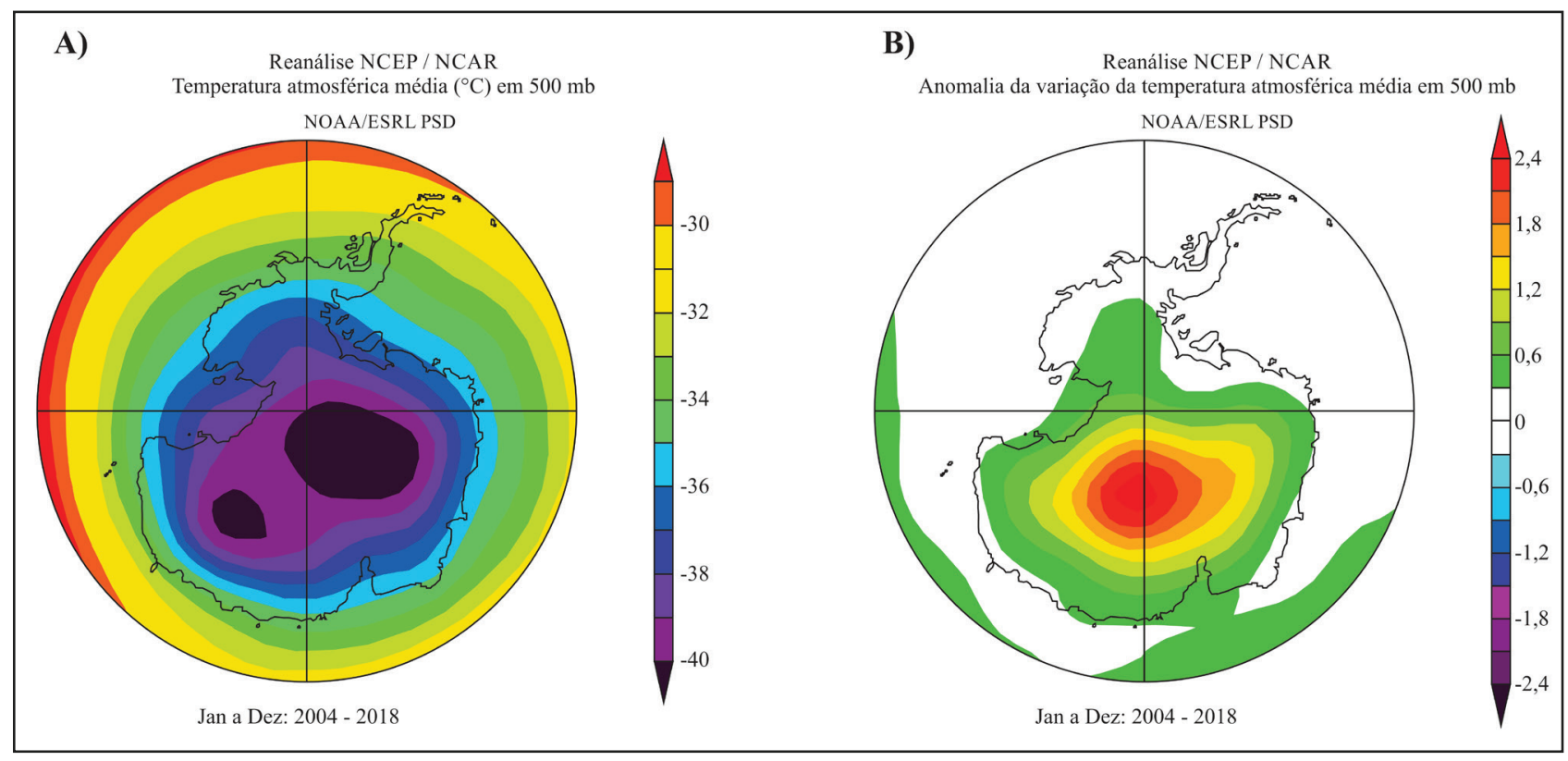

Figura 15. Dados de reanálise NCEP/NCAR para o período 2004-2018. A) Temperatura atmosférica média $\left({ }^{\circ} \mathrm{C}\right)$ em $500 \mathrm{mb}$; B) Anomalia dessa variação, também em 500 mb (Fonte: NOAA ESRL PSD).

Figure 15. NCEP / NCAR reanalysis data for the 2004-2018 period. A) The mean atmospheric temperature $\left({ }^{\circ} \mathrm{C}\right)$ in $500 \mathrm{mb}$; B) Anomaly of this variation also in $500 \mathrm{mb}$ (Source: NOAA ESRL PSD). 
A fim de demonstrar a mudança da velocidade dos ventos de oeste ao redor do continente antártico, gerou-se um modelo da anomalia na zona dos ventos (Fig. 16), para o período 1957-2018, menos o período 19572003. O modelo utiliza os dados de reanálise da velocidade do vento em $\mathrm{m} \mathrm{s}^{-1}$, numa altura de $500 \mathrm{mb}$. Nota-se o aumento da anomalia positiva dos ventos zonais no entorno da Antártica, enquanto que em locais sobre o continente, essa anomalia diminui, demonstrando uma redução da velocidade dos ventos devido ao isolamento resultante da intensificação do vórtice.

A tendência positiva do SAM também é observada pela análise da variação da altura geopotencial da atmosfera. Conforme o SAM tende a ficar positivo ao redor da Antártica, a pressão atmosférica diminui sobre o continente. A figura 17 apresenta a variação da anomalia da pressão atmosférica, numa altura de 500 mb, entre 1957-2003 e 2004-2018. Os dados de reanálise NCEP/NCAR também estão disponíveis no site da NOAA ESRL PSD. Pelo contraste de cores das duas imagens (Fig. 7), observa-se a diferença entre a anomalia negativa para o período 1957-2003, indicando a diminuição da pressão, ou seja, o SAM está em sua fase positiva, e a anomalia positiva no período
2004-2018, a qual mostra com clareza a mudança do comportamento.

Thompson \& Solomon (2002) sugeriram que a alteração do SAM, caracterizada durante a estação de verão-outono, devido ao fluxo circumpolar mais forte contribui substancialmente ao aquecimento observado sobre a Península Antártica e a Patagônia e para o resfriamento sobre a Antártida Oriental e o platô Antártico. Essa hipótese foi corroborada por uma análise de uma série de dados de temperatura da superfície antártica derivada dos sensores Temperature Humidity Infrared Radiometer (THIR) e Advanced Very High Resolution Radiometer (AVHRR) abordo dos satélites Nimbus 4 e NOAA respectivamente, adquirida em 1979 (Kwok\& Comiso, 2002). Além disso, Marshall (2002) mostrou que houve de fato um aumento estatisticamente significativo na intensidade dos ventos de oeste da troposfera desde a década de 1970 no norte da Península. A tendência positiva no SAM resultou no fortalecimento dos ventos circumpolar de oeste em 15\% (Marshal, 2003), contribuindo para a maior variabilidade espacial da mudança de temperatura atmosférica na Antártica (Kwok \& Comiso, 2002; Thompson \& Solomon, 2002; Schneider et al., 2004; Marshall, 2007).

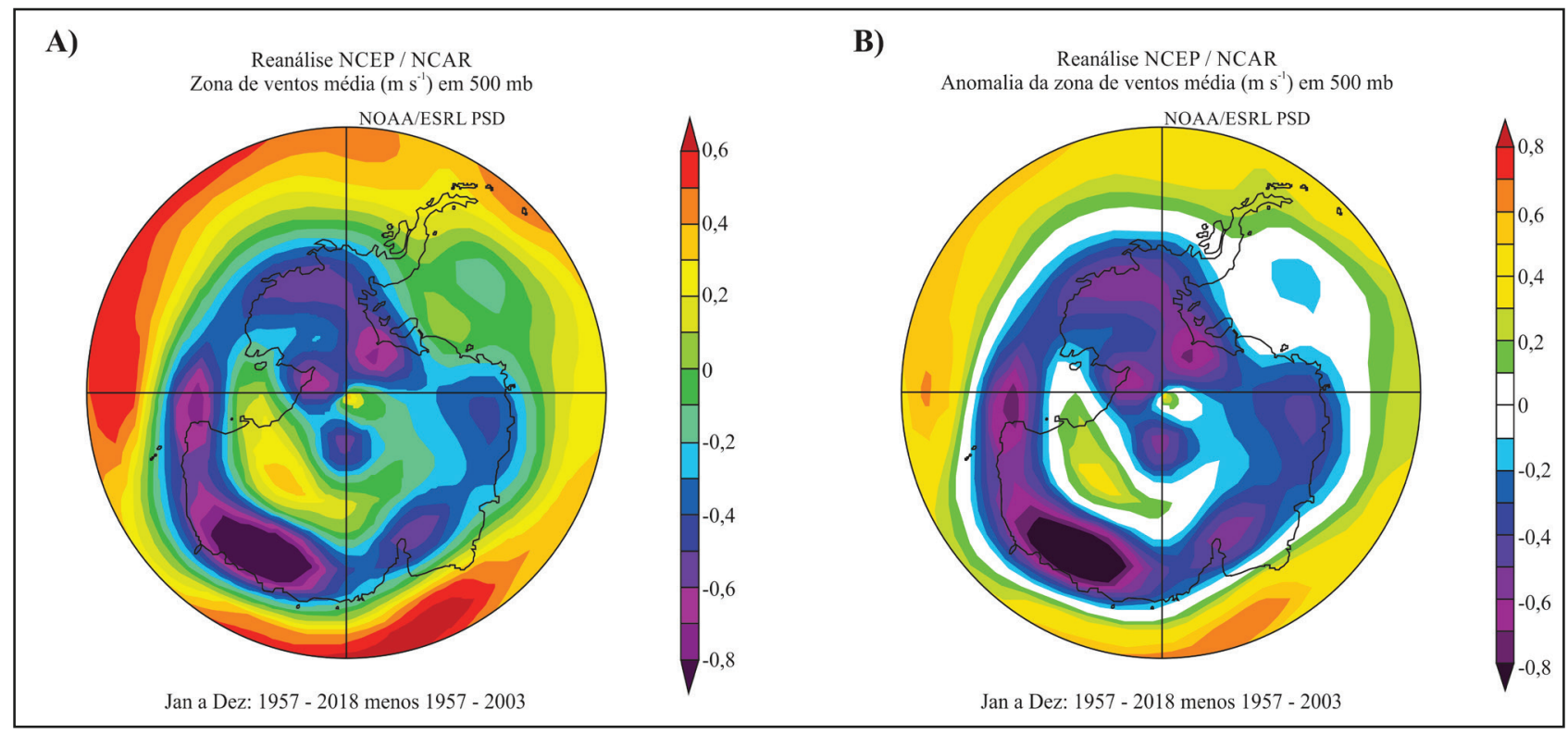

Figura 16. Dados de reanálise NCEP/NCAR para o período 1957-2018, menos 1957-2003. A) Zona de ventos média $\left(\mathrm{m} \mathrm{s}^{-1}\right)$, a uma altura de $500 \mathrm{mb}$; B) Anomalia da zona de ventos $\left(\mathrm{m} \mathrm{s}^{-1}\right)$, a uma altura de $500 \mathrm{mb}$. (Fonte: NOAA ESRL PSD). Figure 16. NCEP / NCAR reanalysis data for the 1957-2018 minus 1957-2003 period. A) the zonal wind composite mean $\left(\mathrm{m} \mathrm{s}^{-1}\right)$ at a height of $500 \mathrm{mb}$; anomaly variation of the wind zone $\left(\mathrm{m} \mathrm{s}^{-1}\right)$ at a height of $500 \mathrm{mb}$ (Source: NOAA ESRL PSD). 


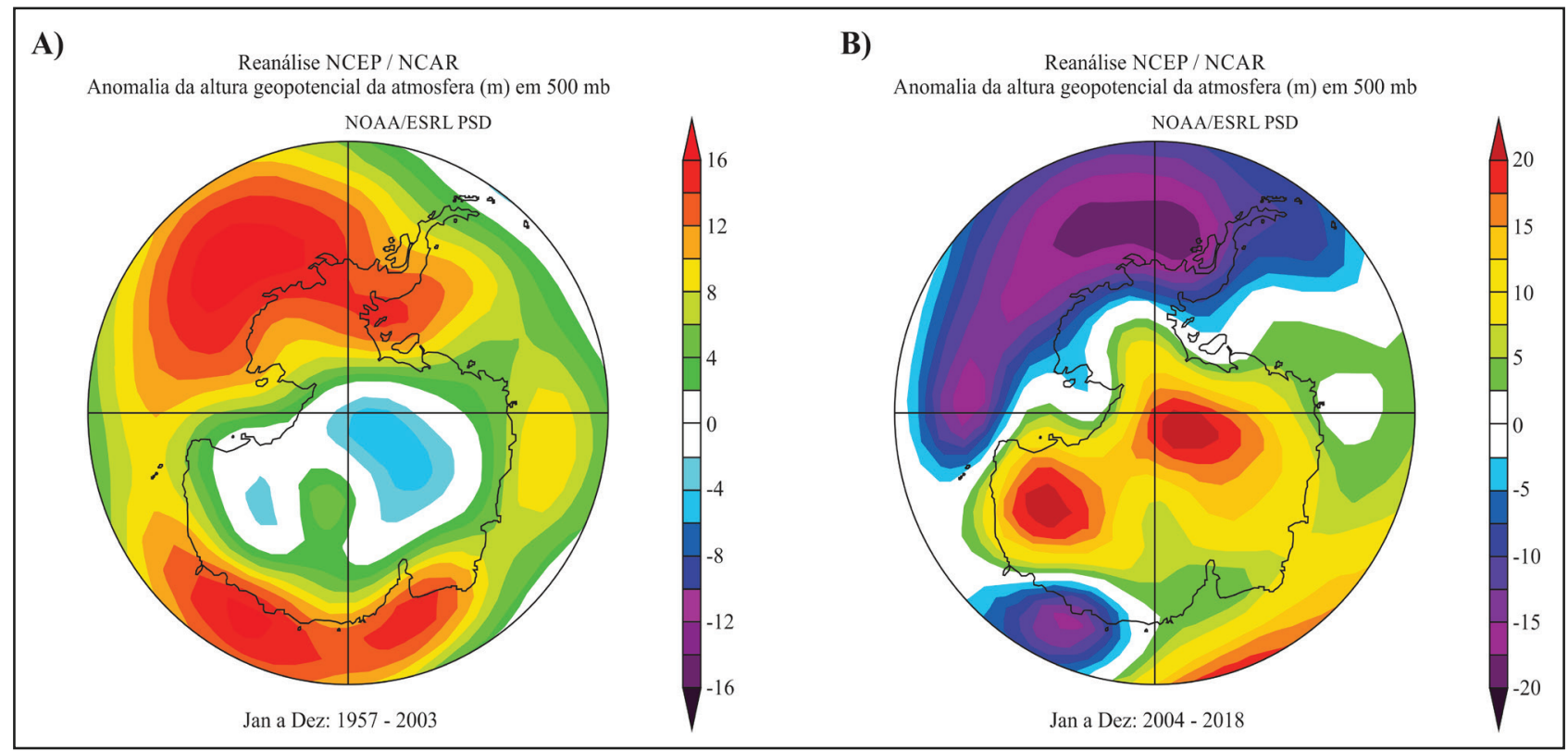

Figura 17. Dados de reanálise NCEP/NCAR para o período 1957-2018. A) Anomalia da altura geopotencial da atmosfera (m), em 500 mb, no período de 1957-2003; B) A mesma anomalia no período de 2004-2018 (Fonte: NOAA ESRL PSD).

Figure 17. NCEP / NCAR reanalysis data for the 1957-2018 period. A) The geopotential height anomaly of the atmosphere $(\mathrm{m})$, in $500 \mathrm{mb}$, in the period 1957-2003; B) The same anomaly in the period 2004-2018 (Source: NOAA ESRL PSD).

\section{Conclusões}

O testemunho de firn IC-02 $\left(88^{\circ} 01^{\prime} 21,3^{\prime \prime} \mathrm{S}\right.$ e $\left.82^{\circ} 04^{\prime} 21,7^{\prime \prime} W\right)$ foi submetido a análises glacioquímicas que confirmaram a relação já esperada entre as razões isotópicas $\left(\delta \mathrm{D}\right.$ e $\left.\delta^{18} \mathrm{O}\right)$ e as variações geográficas e temporais, pela sazonalidade da precipitação, o local fonte da evaporação, o transporte do vapor d'água e os processos pós-deposicionais. O sistema de derretimento contínuo e o sistema Picarro demostraram alta eficiência na preparação e análise das amostras. A relação linear entre o $\delta \mathrm{D}$ e o $\delta^{18} \mathrm{O}\left(\delta \mathrm{D}=8,28 \delta^{18} \mathrm{O}+17,73 ; \mathrm{R}^{2}=0,95\right)$ respeita a linha de Craig (1961) para água meteórica.

Os padrões sazonais de $\delta \mathrm{D}, \quad \delta^{18} \mathrm{O}$, $\mathrm{Na}^{+}$e nsSSO $_{4}^{-2}$ são evidentes nos perfis estratigráficos das amostras do testemunho, isso permitiu estimativas confiáveis da idade e taxa de acumulação, de $85 \pm 3$ anos e $152 \pm 64 \mathrm{~mm} \mathrm{ano}^{-1}$, respectivamente. O erro da datação é devido a dúvidas quanto à variação iônica sazonal em alguns intervalos de profundidade, mesmo com a observação em mais de um perfil iônico e isotópico.

Constatou-se a existência de uma relação estatisticamente significante entre a taxa de acumulação e $\delta \mathrm{D}$ (desde 1918, $\mathrm{R}^{2}=0,1818$; desde $\left.1957, R^{2}=0,2336\right)$. Outras correlações, como a temperatura com $\delta \mathrm{D}$ ou taxa de acumulação, são ausentes de significância estatística $(\alpha>0,005), \quad$ o que inviabiliza quaisquer interpretações da série de dados. A diminuição da média anual de $\delta \mathrm{D}$ correlacionado ao aumento da taxa de acumulação confirma a influência da temperatura sobre o fracionamento isotópico, já que precipitação no inverno é muito maior que no verão na Antártica. Além disso, o local de perfuração do IC-02, a $2.621 \mathrm{~m}$ de altitude, resulta em temperatura atmosférica mais baixa quando comparado a locais de menor altitude e mais próximos a costa. Este resultado corrobora a hipótese de que as variações espaciais de $\delta D$ estão fortemente relacionadas com as mudanças espaciais da temperatura, as quais são diretamente afetadas por fatores geográficos.

O clima da Antártica é extremamente sensível a qualquer perturbação em um de seus componentes, tal como aspectos químicos e físicos da atmosfera. A alteração do equilíbrio químico atmosférico afeta a distribuição da atmosfera antártica, como a redução do ozônio estratosférico que esfria a região. Isso reduz a pressão atmosférica na região com carência de ozônio, aumentando a velocidade dos ventos de oeste ao redor do continente antártico. 0 
testemunho IC-02 corresponde ao período anterior a uma mudança de tendência na temperatura atmosférica no início da década de 2000, em que o platô antártico deixa de esfriar e passa apresentar anomalias positivas da temperatura. O período anterior à década de 1970 corresponde à fase negativa do SAM.

O aumento da acumulação anual de neve (de 17\% entre 1974 e 2003) no sítio do testemunho IC-02 foi concomitante com a redução na razão isotópica $\delta \mathrm{D}$. Tal observação está de acordo com o maior isolamento do platô antártico associado à fase positiva do SAM observada desde 1970. Ao considerarmos o maior isolamento do interior da Antártica e o aumento do vento zonal, observados nos campos de anomalias de altura geopotencial, zona de ventos e temperatura em 500 mb da reanálise NCEP/NCAR para o período do estudo, associados com uma grande variabilidade de excesso de deutério (d) nas amostras do IC-02, deve-se considerar também a hipótese que o aumento da acumulação anual de neve seja associado a maior mobilização de neve à deriva (drift snow) até o sítio de deposição. Isto ocorre por conta da maior advecção de massas de ar oceânicas (Amundsen, Bellingshausen, Weddell e Lazarev) que são determinantes no aumento da acumulação anual de neve no continente.

Vale ressaltar, no entanto, que as informações obtidas através de um único testemunho de firn são insuficientes para a construção de modelos mais avançados que demonstrem possíveis aumentos ou diminuições da temperatura atmosférica na escala continental ou mesmo regionais.

Agradecimentos. Este estudo é parte das investigações do Programa Antártico Brasileiro (PROANTAR) e foi financiado por projetos de pesquisa do Conselho Nacional de Desenvolvimento Científico e Tecnológico (CNPq), Processos 558117/2005-8 e 557053/2009- 9 e do Instituto Nacional de Ciência e Tecnologia da Criosfera (CNPq Processo 465680/2014-3). Os trabalhos de campo foram uma ação colaborativa do Centro de Estudios Científicos de Valdívia (Chile) e do Centro Polar e Climático da UFRGS e contou com o apoio logístico do Exército do Chile e da Força Aérea Chilena (FACh).

\section{Referências}

ADD. Antarctic Digital Database - SCAR. 2019. Scientific Committee on Antarctic Research. Disponível em: < https://scar.org/dataproducts/data/>. Acesso em: 13 mai. 2019.

Bayer da Silva, D. 2011. Interpretação ambiental por cromatografia iônica de um testemunho de firn da Antártica. Porto Alegre, 124 p. Dissertação de mestrado, Programa de Pósgraduação em Geociências, Instituto de Geociências, Universidade Federal do Rio Grande do Sul.

Bromwich, D.H. 1988. Snowfall in high Southern latitudes. Reviews of Geophysics, 26(1): 149168.

Brook, E.J. 2007. Ice core methods/Overview. Oregon, Elsevier, p. 1145-1156.

Casado, M., Landais, A., Masson-Delmotte, V., Genthon, C., Kerstel, E., Kassi, S., Arnaud, L., Picard, G., Prie, F., Cattani, O., Steen-Larsen, H.C., Vignon, E. \& Cermak, P. 2016. Continuous measurements of isotopic composition of water vapour on the East Antarctic Plateau. Atmospheric Chemistry and Physics, 16(13): 8521-8538

Coplen, T.B. 1994. Reporting of stable hydrogen, carbon, and oxygen isotopic abundances (Technical Report). Pure and Applied Chemistry, 66(2): 273-276.

Craig, H. 1961. Isotopic variations in meteoric waters. Science, 133(3465): 1702-1703.

Cuffey, K.M. \& Paterson, W.S.B. 2010. The Physics of Glaciers. $4^{\mathrm{a}}$ ed., Oxford, Pergamon/ Elsevier Science, $704 \mathrm{p}$.

Dansgaard, W. 1964. Stable isotopes in precipitation. Tellus A, 16(4): 436-468.

Dansgaard, W., Johnsen, S.J. \& Clausen, H.B. 1973. Stable isotope glaciology. Meddelelser Grenland, 197(2): 1-53.

Ekaykin, A.A., Lipenkov, V.Y., Barkov, N.I, Petit, J.R. \& Masson-Delmotte, V. 2002. Spatial and temporal variability in isotope composition of recente snow in the vicinity of Vostok Station: Implications for ice-core record interpretation. Annals of Glaciology, 35: 181-186.

Faure, G. \& Mensing, T.M. 2005. Isotopes: Principles and Applications. $3^{a}$ ed., Hoboken, John Wiley, New Jersey, 897 p. 
Fretwell, P., Pritchard, H.D., Vaughan, D.G., Bamber, J.L, Barrand, N.E., Bell, R. Bianchi, C., Bingham, R.G., Blankenship, D.D., Casassa, G., Catania, G., Callens, D., Conway, H., Cook, A.J., Corr, H.F.J., Damaske, D., Damm, V., Ferraccioli, F., Forsberg, R., Fujita, S., Gim, Y., Gogineni, P., Griggs, J.A., Hindmarsh, R.C.A., Holmlund, P., Holt, J.W., Jacobel, R.W., Jenkins, A., Jokat, W., Jordan, T., King, E.C., Kohler, J., Krabill, W., Riger-Kusk, M., Langley, K.A., Leitchenkov, G., Leuschen, C., Luyendyk, B.P., Matsuoka, K., Mouginot, J., Nitsche, F.O., Nogi, Y., Nost, O.A., Popov, S.V., Rignot, E., Rippin, D.M., Rivera, A., Roberts, J., Ross, N., Siegert, M.J., Smith, A.M., Steinhage, D., Studinger, M., Sun, B., Tinto, B.K., Welch, B.C., Wilson, D., Young, D.A., Xiangbin, C. \& Zirizzotti, A. 2013. Bedmap2: improved ice bed, surface and thickness datasets for Antarctica. The Cryosphere, 7(1): 375-393.

Frezzotti, M., Pourchet, M., Flora, O., Gandolfi, S., Gay, M., Urbini, S., Vincent, C., Becagli, S., Gragnami, R., Proposito, M., Severi, Traversi, R., Udisti, R. \& Fily, M. 2004. New estimations of precipitation and surface sublimation in East Antarctica from snow accumulation measurements. Climate Dynamics, 23(7-8): 803-813.

Frezzotti, M., Urbini, S., Proposito, M., Scarchilli, C. \& Gandolfi, S. 2007. Spatial and temporal variability of surface mass balance near Talos Dome, East Antarctica. Journal of Geophysical Research: Earth Surface, 112(2): 1-15.

Gehre, M., Hoefling, R., Kowski, P. \& Strauch, G. 1996. Sample preparation device for quantitative hydrogen isotopic analysis using chromium metal. Analytical Chemistry, 68(24): 4414-4417.

Genthon, C., Krinner, G. \& Deque, M. 1998. Intraannual variability of Antarctic precipitation from weather forecasts and high-resolution climate models. Annals of Glaciology, 27: 488-494.

Ginot, P., Stampfli, F., Stampfli, D., Schwikowski, M. \& Gäggeler, H.W. 2002. FELICS, a new ice core drilling system for high-altitude glaciers. Memoirs of National Institute of Polar Research, Special Issue, 56: 38-48.

Gong, D. \& Wang, S. 1999. Definition of Antarctic oscillation index. Geophysical Research
Letters, 26(4): 459-462

Goursaud, S., Masson-Delmotte, V., Favier, V., Orsi, A. \& Werner, M. 2018. Water stable isotope spatio-temporal variability in Antarctica in 1960-2013: observations and simulations from the ECHAM5-wiso atmospheric general circulation model. Climate of the Past, 14(6): 923-946.

Grieger, J. 2016. Net precipitation of Antarctica: Thermodynamical and dynamical parts of the climate change signal variability of Antarctic precipitation from weather forecasts and high-resolutions climate models. Journal of Climate, 29(3): 907-924.

Hammes, D.F. 2011. Análise e interpretação ambiental da química iônica de um testemunho do manto de gelo da Antártica Ocidental. Porto Alegre, 106 p. Dissertação de mestrado, Programa de Pós-graduação em Geociências, Instituto de Geociências, Universidade Federal do Rio Grande do Sul.

Hornberger, G. 1995. New manuscript guidelines for the reporting of stable hydrogen, carbon, and oxygen isotope ratio data. Water Resources Research, 40(6): 1182.

Hou, S.G., Wang, Y.T. \& Pang, H.X. 2012. Climatology of stable isotopes in Antarctic snow and ice: Current status and prospects. Chinese Science Bulletin, 58(10): 1095-1106.

Huber, C. \& Leuenberger, M. 2003. Fast highprecision on-line determination of hydrogen isotope ratios of water or ice by continuousflow isotope ratio mass spectrometry. Rapid Communications in Mass Spectrometry, 17(12): 1319-1325.

IAEA. International Atomic Energy Agency. 2009. Reference Sheet for VSMOW2 and SLAP2 international measurement standards. IAEA. Viena: International Atomic Energy Agency.

Jouzel, J., Masson-Delmotte, V. 2010. Paleoclimates: what do we learn from deep ice cores? WIREs Climate Change, 1(5): 654-669. Jouzel, J., Alley, R.B., Cuffey, K., Dansgaard, W., Grootes, P., Hoffmann, G., Johnsen, S.J., Koster, R., Peel, D. \& Shuman, C. 1997. Validity of the temperature reconstruction from water isotopes in ice cores. Journal Geophysical Research: Oceans, 102(C12): 26471-26487. Jouzel, J., Masson-Delmotte, V., Cattani, O., 
Dreyfus, G., Falourd, S., Hoffmann, G., Minster, B., Nouet, J., Barnola, J.M. \& Chappellaz, J. 2007. Orbital and millennial Antarctic climate variability over the past 800,000 years. Science, 317(5839): 793-796.

Karpetchko, A., Kyrö, E. \& Knudsen, B.M. 2005. Arctic and Antarctic polar vortex 1957-2002 as seen from the ERA-40 reanalyses. Journal of Geophysical Research, 110(D21109): 1-14.

Kidson, J.W. 1999. Principal modes of Southern Hemisphere low-frequency variability obtained from NCEP-NCAR reanalyses. Journal of Climate, 12(9): 2808-2830.

Kwok, R. \& Comiso, J. 2002. Spatial patterns of variability in Antarctic surface temperature: connections to the Southern Hemisphere Annular Mode and the Southern Oscillation. Geophysical Research Letters, 29(14): 17051708.

Langway Jr., C.C. 1970. Stratigraphic analysis of a deep ice core from Greenland. The Geological Society of America. Special Paper No. 125, $186 \mathrm{p}$.

Langway, C.C., Atau Mitani, H.S. \& Clausen, H.B. 1993. Transformation process observations of polar firn to ice. Annals of Glaciology, 18: 199-202.

Lindau, F.G.L. 2014. Variabilidade do conteúdo iônico da neve e do firn ao longo de um transecto antártico. Porto Alegre, 70 p. Dissertação de Mestrado, Programa de Pósgraduação em Geociências, Instituto de Geociências, Universidade Federal do Rio Grande do Sul.

Lindau, F.G.L, Simões, J.C., Bernardo, R.T., Thoen, I.U., Marques, M.M, Schwanck, F., Marquetto, L., Hammes, D.F, Silva, D.B., Casassa, G., Sneed, S. \& Introne, D.S. 2016. Variabilidade do conteúdo iônico da neve e do firn ao longo de um transecto antártico. Pesquisas em Geociências, 43(3): 213-228.

Lorius, C., Merlivat, L. \& Hagemann, R. 1969. Variation in the mean deuterium contente of precipitations in Antarctic. Journal of Geophysical Research, 74(28): 7027-7031.

Marques, M.M. 2012. Determinação do conteúdo iônico em um testemunho de gelo antártico. Porto Alegre, 68 p. Dissertação de Mestrado, Programa de Pós-graduação em Química, Instituto de Química, Universidade Federal do
Rio Grande do Sul.

Marques, M.M., Peralba, M.C.R., Simões, J.C., Bernardo, R.T., Sneed, S.B. \& Casassa, G. 2014. Analysis of an Antarctic ice core by ion chromatography $\left(\mathrm{Mg}^{2+}, \mathrm{Na}^{+}, \mathrm{Cl}^{-}\right.$, and $\mathrm{SO}_{4}{ }^{2-}$ content). Geochimica Brasiliensis, 28(1): 8996.

Marquetto, L. 2013. Variabilidade das razões de isótopos estáveis de oxigênio da neve ao longo de um transecto antártico. Porto Alegre, 63 p. Dissertação de Mestrado, Programa de Pós-graduação em Geociências, Instituto de Geociências, Universidade Federal do Rio Grande do Sul.

Marquetto, L., Simões, J.C., Casassa, G., Introne, D.S. \& Santos, E.A. 2015. Variações na composição isotópica de oxigênio na neve superficial ao longo de uma travessia antártica. Pesquisas em Geociências, 42(3): 227-238.

Marshall, G.J. 2002. Analysis of recente circulation and termal advection change on the northern Antarctic Peninsula. International Journal of Climatology, 22(12): 1557-1567.

Marshall, G.J. 2003. Trends in the Southern Annular Mode from Observations and Reanalyses. Journal of Climate, 16(24): 41344143.

Marshall, G.J. 2007. Short communication: half-century seasonal relationships between the Southern Annular Mode and Antarctic temperatures. International Journal of Climatology, 27(3): 373-383.

Masson-Delmotte, V., Hou, S., Ekaykin, A., Jouzel, J., Aristarain, A., Bernardo, R.T., Bronwich, D., Cattani, O., Delmotte, M., Falourd, S., Frezzotti, M., Galle, H., Genoni, L., Isaksson, E., Landais, A., Helsen, M.M., Hoffman, G., Lopez, J., Morgan, V., Motoyama, H., Noone, D., Oerter, H., Petit, J., Morgan, V., Motoyama, H., Noone, D., Oerter, H., Petit, J.R., Royer, A., Uemura, R., Schmidt, G.A., Scholosser, E., Simões, J.C., Steig, E.J., Stenni, B., Stievenard, M., Van Den Broeke, M.R., Van de Wal, R.S.W., Van De Berg, W.J., Vimeux, F. \& White, J.W.C. 2008. A review of Antarctic surface snow isotopic composition: Observations, atmospheric circulation, and isotopic modeling. Journal of Climate, 21(13): 3359-3387. 
Merlivat, L. 1978. Molecular diffusivities of $\mathrm{H}_{2}{ }^{16} \mathrm{O}$, $\mathrm{HD}^{16} \mathrm{O}$, and $\mathrm{H}_{2}^{18} \mathrm{O}$ in gases. The Journal of Chemical Physics, 69(6): 2864-2871.

Mosley-Thompson, E., J.F. Paskievitch, A.J. Gow \& L.G. Thompson, 1999. Late 20th Century increase in South Pole snow accumulation. Journal of Geophysical Research, 104(D4), 3877- 3886 .

Mosley-Thompson, E., Kruss, P.D, Thompson, L. G., Pourchet, M. \& Grootes, P. 1985. Snow stratigraphic record at South Pole: potential for paleoclimatic reconstruction. Annals of Glaciology, 7: 26-33.

Neumann, T.A. \& Waddington, E.D. 2004. Efects of firn ventilation on isotopic exchange. Journal of Glaciology, 50(169): 183-194.

NOAA ESRL Physical Sciences Division (PSD). Disponível em: <https://www.esrl.noaa.gov/ psd/webswitch.html>. Acesso em: 01 jun. 2019.

Osterberg, E.C., Handley, M.J., Sneed, S.B., Mayewski, P.A. \& Kreutz, K.J. 2006. Continuous ice core melter system with discrete sampling for major ion, trace element, and stable isotope analyses. Environmental Science \& Technology, 40(10): 3355-3361.

Polvani, L.M. \& Kushner, P.J. 2002. Tropospheric response to stratosphere perturbations in a relatively simple general circulation model. Geophysical Research Letters, 29(7): 11141117.

Raisbeck, G.M., Yiou, F., Jouzel, J. \& Petit, J.R. 1990. 10Be and $\delta^{2} \mathrm{H}$ in polar ice cores as a probe of the solar variability's influence on climate. Philosophical Transactions of the Royal Society of London. Series A, Mathematical and Physical Sciences, 330(1615): 463-469.

Röthlisberger, R., Bigler, M., Hutterli, M., Sommer, S., Stauffer, B., Junghans, H. \& Wagenbach, D. 2000. Technique for continuous highresolution analysis of trace substances in firn and ice cores. Environmental Science \& Technology, 34(2): 338-342.

Schneider, D.P., Steig, E.J. \& Comiso, J.C. 2004. Recent climate variability in Antarctica from satellite-derived temperature data. Journal of Climate, 17(7): 1569-1583.

Schwanck, F. 2012. Determinação de elementos traços em testemunho de firn antártico usando espectrometria de massa. Porto Alegre, 134 p. Dissertação de Mestrado, Programa de Pós-graduação em Geociências, Instituto de Geociências, Universidade Federal do Rio Grande do Sul.

Schwanck, F., Simões, J.C., Handley, M. \& Casassa, G. 2014. Determinação de elementos-traço em testemunho de firn antártico usando ICPMS. Geochimica Brasiliensis, 28(1): 97-107.

Sexton, D.M.H. 2001. The effect of stratospheric ozone depletion on the phase of the Antarctic Oscillation. Geophysical Research Letters, 28(19): 3697-3700.

Simões, J.C. 2004. Glossário da língua portuguesa da neve, do gelo e termos correlatos. Pesquisa Antártica Brasileira, 4: 119-154.

Simões, J.C., Garcia, C.A.E., Evangelista, H., Siqueira-Campos, L., Mata, M.M., Bremer, U.F. 2011. Antártica e as Mudanças Globais. São Paulo: Blucher, v. 9, 169 p.

Tao, G., Yamada, R., Fujikawa, Y., Kudo, A., Zheng, J., Fisher, D.A. \& Koerner, R.M. 2001. Determination of trace amounts of heavy metals in arctic ice core samples using inductively coupled plasma mass spectrometry. Talanta, 55(4): 765-772.

Thompson, D.W.J. \& Solomon, S. 2002. Interpretation of recente Southern Hemisphere climate change. Science, 296: 895-899.

Touzeau, A., Landais, A., Stenni, B., Uemura, R., Fukui, K., Fujita, S., Guilbaud, S., Ekaykin, A., Casado, M., Barkan, E., Luz, B., Magand, O., Teste, G., Le Meur, E., Baroni, M., Savarino, J., Bourgeois, I. \& Risi, C. 2016. Acquisition of isotopic composition for surface snow in East Antarctica and the links to climatic parameters. The Cryosphere, 10: 837-852.

Turner, J. \& Marshall, G.J. 2011. Climate change in the Polar Regions. Cambridge, Cambridge University Press, $433 \mathrm{p}$.

Turner, J., Phillips, T., Thamban, M., Rahaman, W., Marshall, G.J., Wille, J.D., Favier, V., Winton, V.H.L, Thomas, E., Wang, Z., van den Broeke, M., Hosking, J.S. \& Lachlan-Cope, T. 2019. The dominant role of extreme precipitation events in Antarctic snowfall variability. Geophysical Research Letters, 46(6): 3502-3511.

Veen, C.J., Mosley-Thompson, E, Gow, A.J. \& Mark, B.G. 1999. Accumulation at South Pole: 
Comparison of two 900-year records. Journal of Geophysical Research, 104(D24): 31.06731.076.

Vimeux, F., Masson, V., Jouzel, J., Stievenard, M. \& Petit, J.R. 1999. Glacial-interglacial changes in ocean surfasse conditions in the Southern Hemisphere. Nature, 398: 410-413.

Vimeux, F., Masson, V., Jouzel, J., Petit, J.R., Steig, E.J., Stievenard, M., Vaikmae, R. \& White, J.W.C. 2001. Holocene hydrological cycle changes in the Southern Hemisphere documented in East Antarctic deuterium excesso records. Climate Dynamics, 17(7): 503-513.

Wolff, E.W. 2012. Chemical signals of past climate and environment from polar ice cores and firn air. Chemical Society Reviews, 41: 6247-6258. Zhu, Y. \& Newell, R. E. 1998. A proposed algorithm for moisture fluxes from atmosphere rivers. Monthly Weather Review, 126(3): 725-735. 